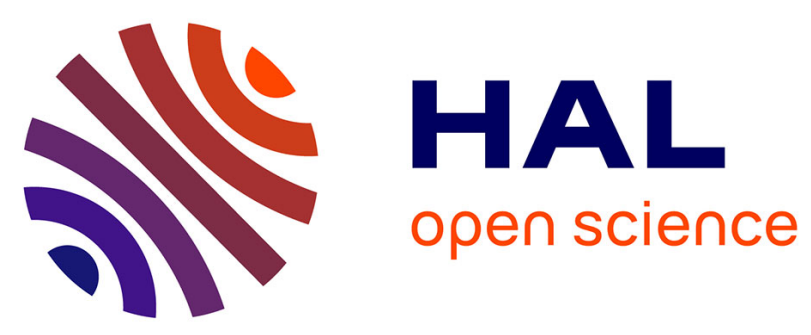

\title{
Old Dog, New Tricks: Innocent, Five-coordinate Cyanocobalt Corroles
}

Ryan Osterloh, Nicolas Desbois, Valentin Quesneau, Stéphane Brandès, Paul Fleurat-Lessard, Yuanyuan Fang, Virginie Blondeau-Patissier, Roberto Paolesse, Claude P Gros, Karl M Kadish

\section{To cite this version:}

Ryan Osterloh, Nicolas Desbois, Valentin Quesneau, Stéphane Brandès, Paul Fleurat-Lessard, et al.. Old Dog, New Tricks: Innocent, Five-coordinate Cyanocobalt Corroles. Inorganic Chemistry, 2020, 59 (12), pp.8562-8579. 10.1021/acs.inorgchem.0c01037 . hal-03198113

\section{HAL Id: hal-03198113 https://hal.science/hal-03198113}

Submitted on 7 May 2021

HAL is a multi-disciplinary open access archive for the deposit and dissemination of scientific research documents, whether they are published or not. The documents may come from teaching and research institutions in France or abroad, or from public or private research centers.
L'archive ouverte pluridisciplinaire HAL, est destinée au dépôt et à la diffusion de documents scientifiques de niveau recherche, publiés ou non, émanant des établissements d'enseignement et de recherche français ou étrangers, des laboratoires publics ou privés. 


\title{
Old Dog, New Tricks: Innocent, Five-coordinate Cyanocobalt Corroles
}

\author{
W. Ryan Osterloh, Nicolas Desbois, Valentin Quesneau, Stéphane Brandès, Paul Fleurat-Lessard, \\ Yuanyuan Fang, Virginie Blondeau-Patissier, Roberto Paolesse,* Claude P. Gros,* and Karl M. Kadish*
}

\begin{abstract}
Three mono-CN ligated anionic cobalt $\mathrm{A}_{3}$-triarylcorroles were synthesized and investigated as to their spectroscopic and electrochemical properties in $\mathrm{CH}_{2} \mathrm{Cl}_{2}$, pyridine (Py), and dimethyl sulfoxide (DMSO). The newly synthesized corroles provide the first examples of air-stable cobalt corroles with an anionic axial ligand and are represented as $\left[(\mathrm{Ar})_{3} \mathrm{CorCo}^{\mathrm{III}}(\mathrm{CN})\right]^{-} \mathrm{TBA}^{+}$, where Cor is the trivalent corrole macrocycle, $\mathrm{Ar}$ is $\mathrm{p}-(\mathrm{CN}) \mathrm{Ph}, \mathrm{p}-\left(\mathrm{CF}_{3}\right) \mathrm{Ph}$, or $\mathrm{p}-(\mathrm{OMe}) \mathrm{Ph}$, and $\mathrm{TBA}^{+}$is the tetra-n-butylammonium (TBA) cation. Multiple redox reactions are observed for each mono-CN derivative with a key feature being a more facile first oxidation and a more difficult first reduction in all three solvents as compared to all previously examined corroles with similar meso- and $\beta$-pyrrole substituents. Formation constants (log K) for conversion of the five-coordinate mono- $\mathrm{CN}$ complex to its six-coordinate bis- $\mathrm{CN}$ form ranged from $10^{2.8}$ for $\mathrm{Ar}=\mathrm{p}$ - $(\mathrm{OMe}) \mathrm{Ph}$ to $10^{4.7}$ for $\mathrm{Ar}=\mathrm{p}-(\mathrm{CN}) \mathrm{Ph}$ in $\mathrm{DMSO}$ as determined by spectroscopic methodologies. The in situ generated bis-CN complexes, represented as $[(\mathrm{Ar}) 3 \mathrm{CorCoIII}(\mathrm{CN}) 2] 2-(\mathrm{TBA}+) 2$, and the mixed ligand complexes, represented as [(Ar)3CorCoIII $(\mathrm{CN})$ (Py)]-TBA+, were also investigated as to their electrochemical and spectroscopic properties. UV-visible spectra and electrode reactions of the synthesized mono- $\mathrm{CN}$ derivatives are compared with the neutral mono-DMSO cobalt corrole complexes and the in situ generated bis- $\mathrm{CN}$ and bis-Py complexes, and the noninnocent (or innocent) nature of each cobalt corrole system is addressed. The data demonstrate the ability of the $\mathrm{CN}$ - axial ligand(s) to stabilize the high-valent forms of the metallocorrole, leading to systems with innocent macrocyclic ligands. Although a number of six-coordinate cobalt(III) corroles with $\mathrm{N}$-donor ligands were characterized in the solid state, a dissociation of one axial ligand readily occurs in nonaqueous solvents, and this behavior contrasts with the high stability of the currently studied bis- $\mathrm{CN}$ adducts in $\mathrm{CH} 2 \mathrm{Cl} 2$, pyridine, or DMSO. Linear free energy relationships were elucidated between the meso-phenyl Hammett substituent constants $(\Sigma \sigma)$ and the measured binding constants, the redox potentials, and the energy of the band positions in the mono$\mathrm{CN}$ and bis-CN complexes in their neutral or singly oxidized forms, revealing highly predictable trends in the physicochemical properties of the anionic corroles.
\end{abstract}

\section{INTRODUCTION}

The electrochemical and spectroscopic properties of numerous corroles possessing a wide variety of meso- and $\beta$-pyrrole substituents have been reported over the last three decades. ${ }^{1-8}$ Many of these reports have focused on the use of these compounds for applications as redox and bioinspired catalysts $^{9-25}$ or sensors, ${ }^{26-36}$ with the focal point of cobalt corrolate application involving oxygen reduction ${ }^{12,23-25}$ and carbon monoxide detection. ${ }^{31-36}$ Moreover, a particular emphasis of corrole research has been placed on unveiling the electronic configuration of the molecule ${ }^{4,37-40}$ to aid in the design of new catalysts. ${ }^{41}$ The propensity of the corrole macrocycle to behave as a noninnocent ligand under specific conditions has often hindered the ability to definitively assign an exact metal and ligand oxidation state, but published reports from our laboratory ${ }^{2,18,42-50}$ and others ${ }^{13,21,26,37,38,51-55}$ have clearly demonstrated that noninnocent corrole macrocycles are significantly easier to reduce than innocent macrocyclic systems having the same formal oxidation state of the central metal ion, thus providing insights into the electronic configuration of the molecule.

Numerous four- and five-coordinate metallocorroles with copper, cobalt, and iron have been shown to possess an oxidized corrole ligand and a reduced metal ion, ${ }^{1-3,26}$ and these complexes were assigned as having a noninnocent macrocyclic ligand in its cation-radical $\left(\mathrm{Cor}^{\bullet 2-}\right)$ form rather than the formal trivalent $\mathrm{Cor}^{3-}$ anion. Many of these 
Chart 1. Structures and Numbering of Investigated Cobalt Triarylcorroles with $p$ - $(\mathrm{CN}) \mathrm{Ph}, p-\left(\mathrm{CF}_{3}\right) \mathrm{Ph}$, or $p$ - $(\mathrm{OMe}) \mathrm{Ph} m e s o-$ Substituents
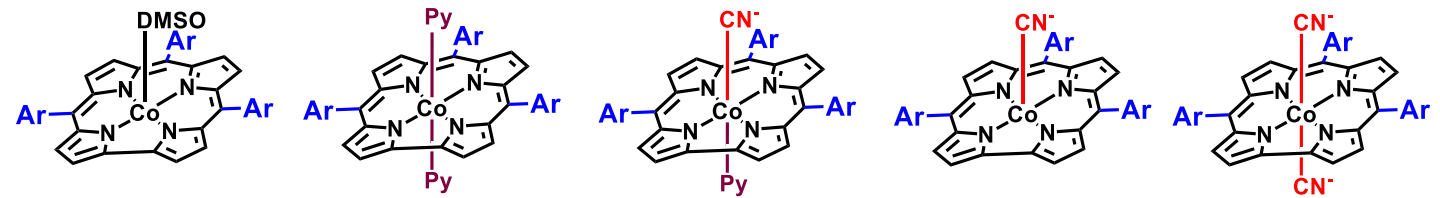

\begin{tabular}{ccc}
$\mathrm{Ar}$ & {$\left[(\mathrm{Ar})_{3} \mathrm{CorCo}(\mathrm{DMSO})\right]$} & {$\left[(\mathrm{Ar})_{3} \mathrm{CorCo}(\mathrm{Py})_{2}\right]$} \\
\hline & $1(\mathrm{DMSO})$ & $1(\mathrm{Py})_{2}$ \\
& $2(\mathrm{DMSO})$ & $2(\mathrm{Py})_{2}$ \\
& & $3(\mathrm{Py})_{2}$
\end{tabular}

$\left[(\mathrm{Ar})_{3} \operatorname{CorCo}(\mathrm{CN})(\mathrm{Py})\right]^{-}$

$\left[(\mathrm{Ar})_{3} \operatorname{CorCo}(\mathrm{CN})\right]^{-}$

$\left[(\mathrm{Ar})_{3} \operatorname{CorCo}(\mathrm{CN})_{2}\right]^{2-}$

$1(\mathrm{CN})(\mathrm{Py})$
$2(\mathrm{CN})(\mathrm{Py})$
$3(\mathrm{CN})(\mathrm{Py})$

$\begin{array}{ll}1(\mathrm{CN}) & 1(\mathrm{CN})_{2} \\ 2(\mathrm{CN}) & 2(\mathrm{CN})_{2} \\ 3(\mathrm{CN}) & 3(\mathrm{CN})_{2}\end{array}$

complexes with noninnocent macrocycles have also been shown to undergo multiple reductions and oxidations in nonaqueous media, and a conversion between the different oxidation states of both the central metal ion and the corrole macrocyclic ligand is easily achieved through either electrochemical or synthetic methods, ${ }^{37,42,56}$ consequently leading to a shift from a noninnocent to an innocent metallocorrole system.

Both direct and indirect spectroscopic criteria, such as X-ray absorption spectroscopy (XAS), electron paramagnetic resonance spectroscopy, and UV-visible spectroscopy, laid out by Ganguly and Ghosh ${ }^{57}$ have been used to classify ligand noninnocence. In our own reports, we established an electrochemical litmus test, where the existence of extremely facile reductions $(\sim 0.00$ to $-0.20 \mathrm{~V}$ vs saturated calomel electrode (SCE)) for transition-metal corroles can be used as one criterion to establish the presence of a noninnocent ligand in the case of metallocorroles with iron, cobalt, nickel, or copper. $^{2,43,45,47-49}$ For example, in the case of cobalt triarylcorroles, the four-coordinate complexes are reduced at the macrocycle (eq 1), while the six-coordinate species are reduced at the central metal ion (eq 2), giving, in both cases, the same cobalt(II) reduction product.

$$
\begin{aligned}
& (\mathrm{Ar})_{3} \mathrm{Cor}^{\bullet} \mathrm{Co}^{\mathrm{II}}+\mathrm{e}^{-} \rightleftharpoons\left[(\mathrm{Ar})_{3} \mathrm{CorCo}^{\mathrm{II}}\right]^{-} \\
& (\mathrm{Ar})_{3} \mathrm{CorCo}^{\mathrm{III}}(\mathrm{L})_{2}+\mathrm{e}^{-} \rightleftharpoons\left[(\mathrm{Ar})_{3} \mathrm{CorCo}^{\mathrm{II}}\right]^{-}+2 \mathrm{~L}
\end{aligned}
$$

Although the same final $\left[(\mathrm{Ar})_{3} \mathrm{CorCo}^{\mathrm{II}}\right]^{-}$product is formed in both cases, the difference in thermodynamic half-wave potentials for the one-electron addition can be significant, varying by as much as $1.0 \mathrm{~V}$ depending on the type of axial ligand and specific Ar substituents. ${ }^{38,48,58}$

One problem with elucidating the effect of axial coordination on the redox potentials of hexacoordinate cobalt corroles is the lability of the axial ligand(s) in solution, which results in a concentration-dependent complexation where one, or both, ligands dissociate in dilute solutions. In search of nonlabile coordinating ligands, we recently investigated the possible binding of anionic ligands to neutral cobalt triarylcorroles and found that 10 of the 11 investigated anionic ligands $\left(\mathrm{PF}_{6}^{-}\right.$, $\mathrm{BF}_{4}^{-}, \mathrm{HSO}_{4}^{-}, \mathrm{ClO}_{4}^{-}, \mathrm{Br}^{-}, \mathrm{I}^{-}, \mathrm{Cl}^{-}, \mathrm{OAc}^{-}, \mathrm{F}^{-}, \mathrm{OTs}^{-}$) were unable to bind to the cobalt center of the neutral complex, with the only exception being $\mathrm{CN}^{-}$, where a stepwise formation of both mono- and bis-CN adducts was observed in solutions of $\mathrm{CH}_{2} \mathrm{Cl}_{2}$ (eqs 3 and 4 ). ${ }^{47}$

$$
\begin{aligned}
& (\mathrm{Ar})_{3} \mathrm{Cor}^{\bullet} \mathrm{Co}^{\mathrm{II}}(\mathrm{DMSO})+\mathrm{CN}^{-} \\
& \rightleftharpoons\left[(\mathrm{Ar})_{3} \mathrm{CorCo}^{\mathrm{III}}(\mathrm{CN})\right]^{-}+\mathrm{DMSO} \\
& {\left[(\mathrm{Ar})_{3} \mathrm{CorCo}^{\mathrm{III}}(\mathrm{CN})\right]^{-}+\mathrm{CN}^{-}} \\
& \rightleftharpoons\left[(\mathrm{Ar})_{3} \mathrm{CorCo}^{\mathrm{III}}(\mathrm{CN})_{2}\right]^{2-}
\end{aligned}
$$

The final in situ generated bis-CN adducts in eq 4 were remarkably stable, independent of the Ar group on the corrole, and exhibited the most-facile oxidation and most difficult reduction of any cobalt corrole system investigated.

After publication of our initial report on anion interaction with cobalt corroles ${ }^{47}$ we attempted to isolate bis-CN derivatives in the solid state for further analysis but obtained, in each case, only the mono- $\mathrm{CN}$ complexes, three of which are characterized in the current study. The chemical properties of these species are described on the following pages and compared to the mono-DMSO precursors, [ $(\mathrm{Ar})_{3} \mathrm{CorCo}-$ (DMSO) $],{ }^{47}$ the corresponding in situ generated bis-CN and bis-Py adducts, as well as the transient mixed-ligand adducts containing one $\mathrm{CN}^{-}$and one pyridine axial ligand. The monoand bis-cyanocobalt complexes are the first known examples of air-stable cobalt corroles with anionic axial ligands and are represented as $\left[(\mathrm{Ar})_{3} \operatorname{CorCo}(\mathrm{CN})_{n}\right]^{n-}\left(\mathrm{TBA}^{+}\right)_{n}$, where Cor is the trivalent corrole macrocycle, $\mathrm{Ar}$ is $p-(\mathrm{CN}) \mathrm{Ph}, p-\left(\mathrm{CF}_{3}\right) \mathrm{Ph}$, or $p-(\mathrm{OMe}) \mathrm{Ph}$, and $n=1$ or 2 , as shown in Chart 1 . $\mathrm{TBA}^{+}$is the tetra- $n$-butylammonium (TBA) cation.

\section{EXPERIMENTAL SECTION}

Materials and Instrumentation. All chemicals and solvents were of the highest electrochemical grade available and were used without further purification. Anhydrous dichloromethane $\left(\mathrm{CH}_{2} \mathrm{Cl}_{2}, \geq 99.8 \%\right)$, anhydrous dimethyl sulfoxide (DMSO, $\geq 99.9 \%$ ), and anhydrous pyridine (Py, $\geq 99.8 \%$ ) were purchased and used as received. Tetra- $n$ butyl-ammonium perchlorate (TBAP, $\geq 99.0 \%$ ) and $95.0 \%$ tetra- $n$ butyl-ammonium cyanide (TBACN) were purchased from Sigma Chemical Co. and stored in a desiccator until used.

NMR solvents were purchased from Eurisotope and were used without further purification. ${ }^{1} \mathrm{H}$ NMR spectra were recorded on a Bruker Avance III 500 spectrometer operating at $500 \mathrm{MHz}$ and available at the PACSMUB-WPCM technological platform, which relies on the "Institut de Chimie Moléculaire de l'Université de Bourgogne" and SATT SAYENS "TM", a Burgundy University private subsidiary. All NMR chemical shift values are expressed in ppm. ${ }^{1} \mathrm{H}$ spectra were calibrated using the residual peak of chloroform at 7.26 $\mathrm{ppm}$, and ${ }^{19} \mathrm{~F}$ spectra were calibrated with an internal reference $\left(\mathrm{CFCl}_{3}\right)$. 
UV-visible spectra were recorded on a Hewlett-Packard model 8453 diode array or on a Varian Cary 50 spectrophotometer. Quartz cells with optical path lengths of $10 \mathrm{~mm}$ were used. Infrared spectra were recorded on an IR Fourier transform (FT) Bruker Vertex 70v via $\mathrm{KBr}$ pellets.

Electrospray ionization (ESI) mass spectra were recorded on an LTQ Orbitrap XL (THERMO) instrument for high resolution (HR) mass spectrometry (MS) spectra and on an AmaZon SL (Bruker) instrument for the low-resolution mass spectrometry (LRMS) spectra.

Cyclic voltammetry was performed at $298 \mathrm{~K}$ using an EG\&G Princeton Applied Research 173 potentiostat/galvanostat, where a three-electrode system was employed for cyclic voltammetric measurements and consisted of a glassy carbon working electrode, a platinum counter electrode, and a saturated calomel reference electrode. The SCE was separated from the bulk of the solution by a fritted glass bridge of low porosity purchased from Gamry Instruments, which contained the solvent/supporting electrolyte mixture. Thin-layer UV-vis spectroelectrochemical experiments were performed with a commercially available thin-layer cell from Pine Instruments Inc. with a platinum honeycomb working electrode. Potentials were applied and monitored with an EG\&G PAR Model 173 potentiostat. High-purity $\mathrm{N}_{2}$ from Trigas was used to deoxygenate the solution, and a stream of nitrogen was kept over the solution during each electrochemical and spectroelectrochemical experiment.

Determination of Binding Constants. Ligand binding constants were calculated by two methods, one spectroscopic and one electrochemical. In the spectroscopic method, changes in the UVvisible spectra were monitored during titrations of $1(\mathrm{CN})-3(\mathrm{CN})$ with the ligand $\mathrm{L}$ (in this case $\mathrm{CN}^{-}$) and the resulting data used to calculate formation constants for ligand binding using the Hill eq (eq $5),{ }^{59}$ where $A_{0}$ is the measured absorbance for a specific concentration of added ligand $[\mathrm{L}], A_{\mathrm{i}}$ is the initial absorbance before addition of the ligand to solution, and $A_{\mathrm{f}}$ corresponds to the final absorbance of the fully coordinated species.

$$
\log \left[\frac{A_{i}-A_{0}}{A_{0}-A_{\mathrm{f}}}\right]=\log K+n \log [\mathrm{L}]
$$

Synthesis of mono-CN Cobalt Corroles. A solution of pentacoordinated cobalt corrole with DMSO $(0.058 \mathrm{mmol})^{47}$ and TBACN (0.174 mmol, 3 equiv) in $\mathrm{CH}_{2} \mathrm{Cl}_{2}(70 \mathrm{~mL})$ was stirred at room temperature for $20 \mathrm{~min}$. After evaporation of the solvent, the residue was filtered through a silica gel column eluted with ethyl acetate $(\mathrm{EtOAc})$ for $2(\mathrm{CN})$ or a mixture of $\mathrm{CH}_{2} \mathrm{Cl}_{2} / \mathrm{EtOAc}(9 / 1$, $\mathrm{v} / \mathrm{v}$ ) for $\mathbf{1}(\mathrm{CN})$ and $3 \mathrm{CN}$.

Tetrabutylammonium mono-CN Cobalt [5,10,15-tris(4-cyanophenyl)] Corrolate. $1(\mathrm{CN})$ was obtained in $86 \%$ yield starting from the mono-(DMSO)cobalt [5,10,15-tris(4-cyanophenyl)]corrole. ${ }^{47} \mathrm{UV}-\mathrm{Vis}\left(\mathrm{CH}_{2} \mathrm{Cl}_{2}\right): \lambda_{\max }(\mathrm{nm})\left(\varepsilon \times 10^{-3} \mathrm{~L} \mathrm{~mol}^{-1} \mathrm{~cm}^{-1}\right)$ 422 (62.7), $568(15.9)$. FTIR $\left(\mathrm{cm}^{-1}\right), \nu_{\mathrm{CN}}$ region $(\mathrm{KBr}): 2115$ (CoCN). ${ }^{1} \mathrm{H}$ NMR $\left(500 \mathrm{MHz}, \mathrm{CDCl}_{3}\right), \delta(\mathrm{ppm}): 9.08(\mathrm{~m}, 2 \mathrm{H}), 8.73$ $(\mathrm{m}, 2 \mathrm{H}), 8.50-8.46(\mathrm{~m}, 6 \mathrm{H}), 8.31(\mathrm{~m}, 4 \mathrm{H}), 8.03(\mathrm{~m}, 6 \mathrm{H}), 2.02(\mathrm{~m}$, $8 \mathrm{H}), 0.94(\mathrm{~m}, 8 \mathrm{H}), 0.85(\mathrm{~m}, 8 \mathrm{H}), 0.71(\mathrm{~m}, 12 \mathrm{H})$. LRMS (ESI, negative mode): $\mathrm{m} / z$ 683.19 $\left[\mathrm{M}-\mathrm{NBu}_{4}\right]^{-}, 683.11$ calcd for $\mathrm{C}_{41} \mathrm{H}_{20} \mathrm{CoN}_{8}$. HR-MS (ESI, negative mode): $\mathrm{m} / z=683.1146$

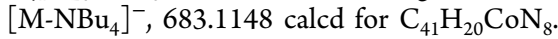

Tetrabutylammonium mono-CN Cobalt [5,10,15-tris(4trifluoromethylphenyl)] Corrolate. 2(CN) was obtained in 52\% yield starting from the mono-(DMSO)cobalt [5,10,15-tris(4trifluoromethylphenyl) $]$ corrole. $^{47} \mathrm{UV}-\mathrm{Vis}\left(\mathrm{CH}_{2} \mathrm{Cl}_{2}\right): \lambda_{\max }(\mathrm{nm})$ $\left(\varepsilon \times 10^{-3} \mathrm{~L} \mathrm{~mol}^{-1} \mathrm{~cm}^{-1}\right) 416(66), 562(14)$. FTIR $\left(\mathrm{cm}^{-1}\right), \nu_{\mathrm{CN}}$ region $(\mathrm{KBr}): 2114(\mathrm{CoCN}) .{ }^{1} \mathrm{H}$ NMR $\left(500 \mathrm{MHz}, \mathrm{CDCl}_{3}\right), \delta(\mathrm{ppm})$ : $8.97(\mathrm{~m}, 2 \mathrm{H}), 8.62(\mathrm{~m}, 2 \mathrm{H}), 8.36(\mathrm{~m}, 4 \mathrm{H}), 8.23(\mathrm{~m}, 2 \mathrm{H}), 8.03-7.94$ $(\mathrm{m}, 10 \mathrm{H}), 2.87(\mathrm{~m}, 2 \mathrm{H}), 2.32(\mathrm{~m}, 2 \mathrm{H}), 1.95-1.84(\mathrm{~m}, 4 \mathrm{H}), 1.25-$ $0.71(\mathrm{~m}, 28 \mathrm{H}) .{ }^{19} \mathrm{~F}$ NMR $\left(470 \mathrm{MHz}, \mathrm{CDCl}_{3}\right) \delta-62.24(\mathrm{~s}, 9 \mathrm{~F})$.

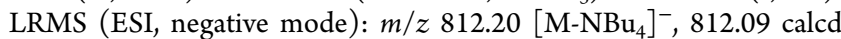
for $\mathrm{C}_{41} \mathrm{H}_{20} \mathrm{CoF}_{9} \mathrm{~N}_{4}$. HR-MS (ESI, negative mode): $\mathrm{m} / z=812.0930$

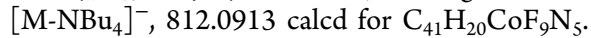

Tetrabutylammonium mono-CN Cobalt [5,10,15-tris(4-methoxylphenyl)] Corrolate. 3(CN) was obtained in $43 \%$ yield starting from the mono-(DMSO)cobalt [5,10,15-tris $(4$ methoxyphenyl)] corrole. ${ }^{47} \mathrm{UV}-\mathrm{Vis}\left(\mathrm{CH}_{2} \mathrm{Cl}_{2}\right): \lambda_{\max },(\mathrm{nm})$ $\left(\varepsilon \times 10^{-3} \mathrm{~L} \mathrm{~mol}^{-1} \mathrm{~cm}^{-1}\right) 417(40), 565(13)$. FTIR $\left(\mathrm{cm}^{-1}\right), \nu_{\mathrm{CN}}$ region $(\mathrm{KBr}): 2109(\mathrm{CoCN})$. LRMS (ESI, negative mode): $\mathrm{m} / z$ $698.17\left[\mathrm{M}-\mathrm{NBu}_{4}\right]^{-}, 698.16$ calcd for $\mathrm{C}_{41} \mathrm{H}_{29} \mathrm{CoN}_{5} \mathrm{O}_{3}$.

Density Functional Theory Computational Details. Quantum-mechanics calculations were performed with the Gaussian 16 software package. ${ }^{60}$ Energy and forces were computed by density functional theory (DFT) with the hybrid M06-2X exchangecorrelation functional. ${ }^{61}$ The solvent effects were modeled using a polarizable continuum model ${ }^{62,63}$ (PCM) as implemented in Gaussian16 to describe the bulk medium (DMSO or pyridine). Geometries were optimized and characterized with the cc-pVTZ basis sets for all atoms. ${ }^{64,65}$ Frequency calculations were performed to estimate the Gibbs free energies at $298 \mathrm{~K}$ and 1 atm at this level. To obtain better binding constants, single points were performed on these geometries with the may-cc-pVTZ basis sets of Truhlar and co-workers. ${ }^{66}$ As the amount of exact exchange is important to accurately estimate the energies of open-shell systems, energies of the different spin states were computed with the B3LYP-D3 functional that includes empirical corrections for dispersion effects from Grimme et. al, ${ }^{67}$ with the def2-SVP basis set. ${ }^{68}$ Spin density images were generated with ChemCraft, Version 1.8. ${ }^{69}$

\section{RESULTS AND DISCUSSION}

Synthesis of Cobalt Corroles. Mono-CN ligated anionic cobalt $\mathrm{A}_{3}$-triarylcorroles were obtained from 1-3(DMSO) $)^{47}$ by ligand exchange using TBACN at room temperature as shown in Scheme 1. The use of the quaternary ammonium

Scheme 1. Synthesis of mono-CN Ligated Cobalt Corroles $1(\mathrm{CN})-3(\mathrm{CN})$

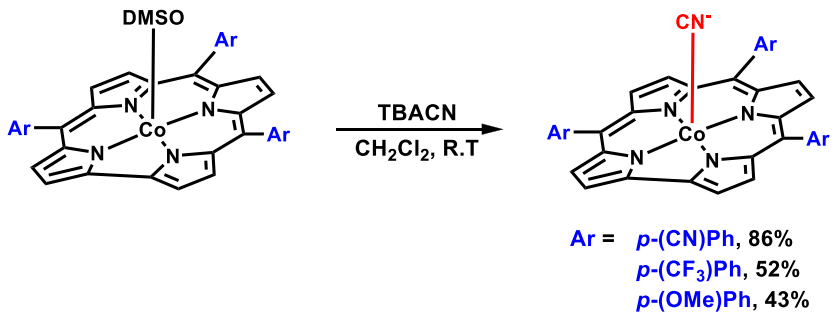

cyanide salt (TBACN) was preferred to $\mathrm{NaCN}$ or $\mathrm{CuCN}$, as it is soluble in most organic solvents and was used in both the previous ${ }^{47}$ and current electrochemical and spectroscopic studies. Three equivalents of TBACN were used, and after column purification, only the mono-CN was isolated. $\mathbf{1}(\mathrm{CN})$ and $2(\mathrm{CN})$ were characterized by proton NMR (see Figures $\mathrm{S} 1$ and S2), while the ${ }^{1} \mathrm{H}$ NMR spectrum of $3(\mathrm{CN})$ was poorly resolved with very broad resonances due perhaps to electrondonating methoxy substituents, which can enhance the presence of oxidized radical species, similar to what has been reported for free-base $\beta$-alkyl corroles. ${ }^{70}$ Resonance signals corresponding to the tetrabutylammonium counterion $\left(\mathrm{TBA}^{+}\right)$ are marked with an asterisk (*) in Figures $\mathrm{S} 1$ and $\mathrm{S} 2$ and are located between 2.02 and $0.85 \mathrm{ppm}$ in the case of $1(\mathrm{CN})$.

A characteristic $\mathrm{CN}$ stretching band is observed in the FTIR spectrum and located at 2115,2114 , and $2109 \mathrm{~cm}^{-1}$ for $1-$ $3(\mathrm{CN})$, respectively. This $\mathrm{CN}$ stretch occurs at higher frequencies as compared to the $\nu_{\mathrm{CN}}$ of free cyanide (2080 $\mathrm{cm}^{-1}$ ), a shift consistent with coordination of the $\sigma$-donating cyanide ligand to a metal ion ${ }^{71}$ and occurs at a frequency similar to that of a reported mono-CN $\mathrm{Co}(\mathrm{III})$ corrolazine, 

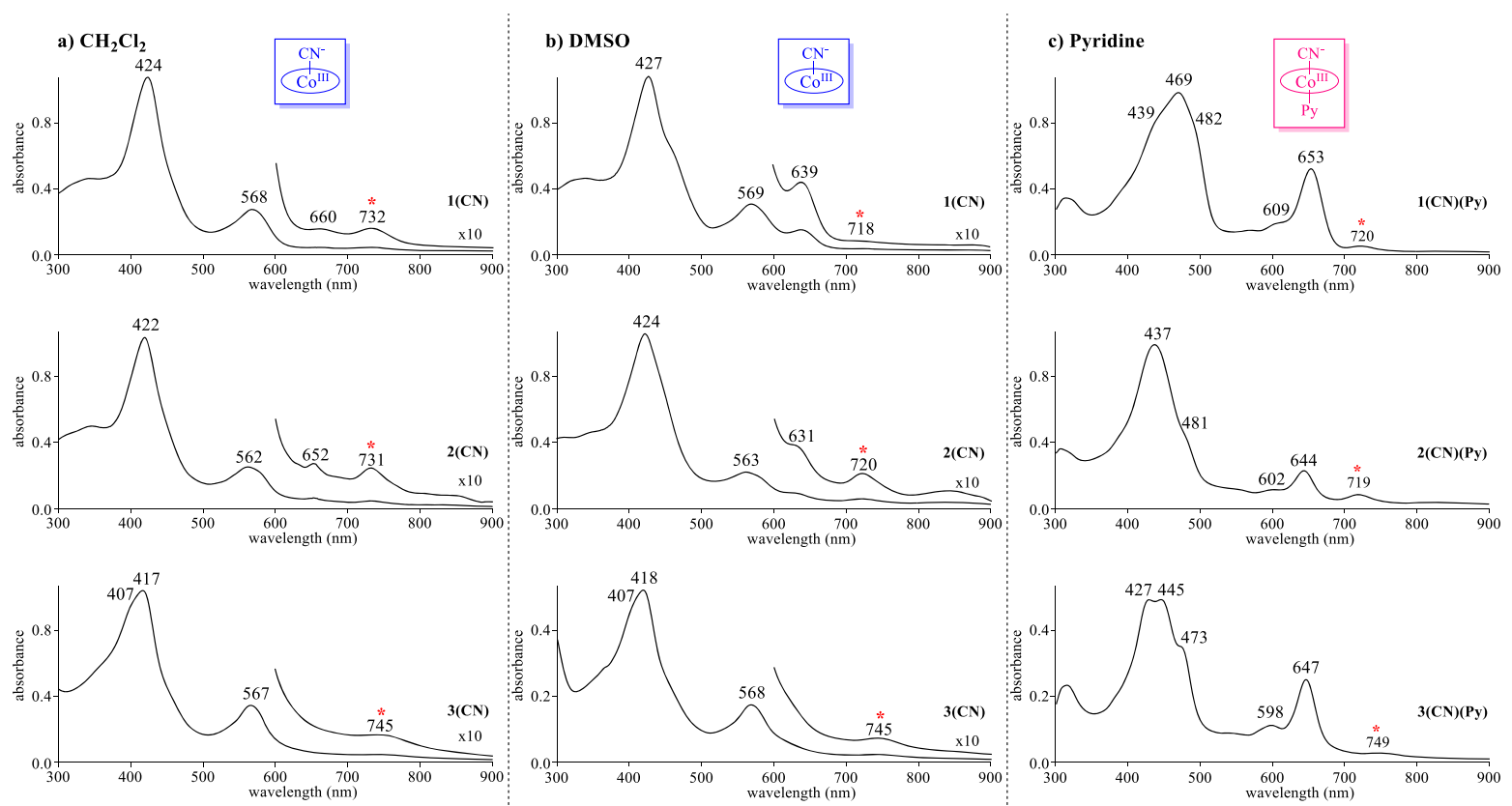

Figure 1. UV-Vis spectra at $\sim 10^{-5} \mathrm{M}$ of the mono-CN adducts in (a) $\mathrm{CH}_{2} \mathrm{Cl}_{2}$ and (b) DMSO and (c) the mixed ligand adducts in pyridine. The band marked with an asterisk $(*)$ is assigned to a partially oxidized form of the corrole (see later discussion).

Table 1. UV-Visible Spectral Data of the Mono-DMSO and Investigated $\left[(\mathrm{Ar})_{3} \mathrm{CorCo}(\mathrm{CN})\right]^{-}(\sim 10-5 \mathrm{M})$ in DMSO and Pyridine Both with and without Excess TBACN ${ }^{a}$

\begin{tabular}{|c|c|c|c|c|c|c|c|c|c|}
\hline \multirow[b]{3}{*}{ solvent } & \multirow[b]{3}{*}{ cpd } & \multicolumn{7}{|c|}{$\lambda, \mathrm{nm}\left(\varepsilon \cdot 10^{-4} \mathrm{M}^{-1} \cdot \mathrm{cm}^{-1}\right)$} & \multirow[b]{3}{*}{ ref } \\
\hline & & & & & \multicolumn{4}{|c|}{ visible region } & \\
\hline & & \multicolumn{3}{|c|}{ Soret region } & \multicolumn{3}{|c|}{ Q band } & $\mathrm{NIR}^{b}$ & \\
\hline \multirow[t]{9}{*}{ DMSO } & 1(DMSO) & $393(4.8)$ & $436(3.8)^{c}$ & & $571(1.2)$ & $630(0.5)$ & & & 47 \\
\hline & 2(DMSO) & $386(4.5)$ & $433(2.4)$ & & $566(1.1)$ & $620(0.4)$ & & & 47 \\
\hline & 3(DMSO) & $405(5.3)$ & $421(5.1)^{c}$ & & $567(1.0)$ & & & & 47 \\
\hline & $1(\mathrm{CN})$ & $427(5.3)$ & & $462(3.0)^{c}$ & $569(1.4)$ & $639(0.6)$ & & $718(0.1)$ & t.w \\
\hline & $2(\mathrm{CN})$ & $424(3.9)$ & & & $563(0.8)$ & $631(0.4)$ & & $720(0.2)$ & t.w \\
\hline & $3(\mathrm{CN})$ & $407(3.8)$ & $418(4.0)$ & & $568(1.4)$ & & & $745(0.1)$ & t.w \\
\hline & $1(\mathrm{CN})_{2}$ & $442(2.4)^{c}$ & $493(5.0)$ & $519(4.9)$ & $580(0.8)$ & $651(0.9)$ & $711(4.1)$ & & t.w \\
\hline & $2(\mathrm{CN})_{2}$ & $440(2.8)$ & $474(3.1)$ & $503(2.8)$ & $566(0.6)$ & $639(0.6)$ & $697(2.0)$ & & t.w \\
\hline & $3(\mathrm{CN})_{2}$ & $430(3.1)$ & $466(3.1)$ & $497(2.9)$ & $563(1.0)$ & $640(0.7)$ & $699(2.3)$ & & t.w \\
\hline \multirow[t]{9}{*}{ pyridine } & $1(\mathrm{Py})_{2}$ & $458(4.5)$ & & & $590(0.6)$ & $631(1.9)$ & & & \\
\hline & $2(\mathrm{Py})_{2}$ & $445(3.1)$ & $455(2.9)$ & & $586(0.5)$ & $624(1.3)$ & & $695(0.2)$ & \\
\hline & $3(\mathrm{Py})_{2}$ & $437(3.0)$ & $456(2.5)$ & & $585(0.4)$ & $630(1.3)$ & & $738(0.1)$ & \\
\hline & $\mathbf{1}(\mathbf{C N})(\mathbf{P y})^{d}$ & 439 & 469 & 482 & 609 & 653 & & 720 & \\
\hline & $2(\mathbf{C N})(\mathbf{P y})^{d}$ & 437 & & 481 & 602 & 644 & & 719 & \\
\hline & $3(\mathbf{C N})(\mathbf{P y})^{d}$ & 427 & 445 & 473 & 598 & 647 & & 749 & \\
\hline & $1(\mathrm{CN})_{2}$ & $442(2.1)$ & $495(3.5)$ & $525(3.0)$ & & $655^{e}(1.4)$ & $718(2.2)$ & & \\
\hline & $2(\mathrm{CN})_{2}$ & $439(3.5)$ & $476(3.0)$ & $507(2.3)$ & & $644^{e}(0.9)$ & $702(1.6)$ & $753(0.3)$ & \\
\hline & $3(\mathrm{CN})_{2}$ & $429(2.7)$ & $446(2.7)$ & $474(2.1)$ & $599(0.6)$ & $648^{e}(1.3)$ & $701(0.7)$ & $768(0.2)$ & \\
\hline
\end{tabular}

${ }^{a}$ The diagnostic band of the six-coordinate complexes are shown in bold. ${ }^{b}$ Bands of oxidized species (see text and refs 16 and 73 ); t.w $=$ this work. ${ }^{c}$ Shoulder peak. ${ }^{d}$ No molar absorptivities are reported for these transient species. ${ }^{e}$ Correspond to the bis $(\mathrm{CN})(\mathrm{Py})$ adducts (see text).

where the monomeric form was shown to display a $\nu_{\mathrm{CN}}$ vibrational band at $2135 \mathrm{~cm}^{-1}$. $^{72}$

Both the oxidation state and electronegativity of the metal center are known to affect the stretching frequency of a bound $\mathrm{CN}$ molecule, ${ }^{71}$ and thus the similarity between the synthesized mono- $\mathrm{CN}$ cobalt corroles and a reported mono$\mathrm{CN} \mathrm{Co}(\mathrm{III})$ corrolazine strongly suggest an innocent corrole system with a true $\mathrm{Co}$ (III) central metal ion; a phenomena that is reinforced by data and discussions provided on the following pages.
UV-Visible Spectra of Mono-CN Derivatives. Earlier spectral characterization of structurally related mono-DMSO and bis-Py cobalt corroles had shown concentration-dependent spectra in $\mathrm{CH}_{2} \mathrm{Cl}_{2}$ owing to the lability of the axial ligands. $^{45-47}$ For example, in the case of the mono-DMSO derivatives a five-coordinate complex was observed when the corroles were dissolved at millimolar concentrations in $\mathrm{CH}_{2} \mathrm{Cl}_{2}$, while a dissociation of the DMSO axial ligand occurred in more dilute $\left(\sim 10^{-5} \mathrm{M}\right)$ solutions, giving the fourcoordinate complexes in each case. In contrast, no such 
concentration-dependent coordination of the cyanide ligand is observed between $10^{-3}$ and $10^{-6} \mathrm{M}$ in either DMSO or $\mathrm{CH}_{2} \mathrm{Cl}_{2}$ solutions.

Examples of the measured UV-visible spectra for $\mathbf{1}(\mathrm{CN})-$ $3(\mathrm{CN})$ in $\mathrm{CH}_{2} \mathrm{Cl}_{2}, \mathrm{DMSO}$, and pyridine at $10^{-5} \mathrm{M}$ are illustrated in Figure 1, and the data in DMSO and pyridine are summarized in Table 1, which also includes the mono-DMSO complexes taken from a previous report. ${ }^{47}$ For clarity we separately summarized spectroscopic data for the same compounds in $\mathrm{CH}_{2} \mathrm{Cl}_{2}$ (see Table $\mathrm{S} 1$ ).

As seen in Figure 1, spectra of the two mono-CN compounds with electron-withdrawing $\mathrm{CN}$ or $\mathrm{CF}_{3}$ mesophenyl substituents $(\mathbf{1}(\mathbf{C N})$ and $\mathbf{2}(\mathbf{C N}))$ are characterized by a sharp Soret band at $422-427 \mathrm{~nm}$ and one or two $\mathrm{Q}$ bands when dissolved in either $\mathrm{CH}_{2} \mathrm{Cl}_{2}$ or DMSO at a concentration of $10^{-5} \mathrm{M}$. Compound $3(\mathrm{CN})$, which has three electrondonating $p$-methoxyphenyl meso-substituents, is characterized by a split Soret band located at $417-418 \mathrm{~nm}$ under both solution conditions and a single Q-band at 567/568 nm in both solvents. The Soret bands of $\mathbf{1}(\mathrm{CN})$ and $\mathbf{2}(\mathrm{CN})$ are redshifted by $34-38 \mathrm{~nm}$ when compared to the corresponding mono-DMSO complexes 1(DMSO) and 2(DMSO) (see Table 1), but almost identical absorption bands are observed at $405-407$ and $418-421 \mathrm{~nm}$ for 3(DMSO) and $3(\mathrm{CN})$ under these solution conditions.

This similarity between UV-visible spectra of $3(\mathrm{CN})$ and 3(DMSO) can be explained by one of two possibilities: (i) the formulations of the absorbing compounds in solution are identical at a concentration of $10^{-5} \mathrm{M}$ in DMSO; that is, both corroles exist as the mono-DMSO adducts with the cyanide ligand having been replaced by DMSO in the case of $3(\mathrm{CN})$ or (ii) the mono-DMSO and mono- $\mathrm{CN}$ adducts of the $p$-OMe substituted corroles have nearly identical UV-visible spectra due to the similar electronic configuration of the compounds in both pentacoordinated complexes. The latter of these two explanations is more likely, since the $\mathrm{CN}^{-}$axial ligand is strongly bound as evidenced by the redox potentials and the electrochemically determined binding constants for a single $\mathrm{CN}^{-}$ligand as described on the following pages.

On the basis of our previous reports, ${ }^{45,47}$ the presence of two $\mathrm{Q}$ bands for $\mathbf{1}(\mathrm{CN})$ and $\mathbf{2}(\mathrm{CN})$ in DMSO (Figure $1 \mathrm{~b}$ ) are assigned as a mixture of the five- and six-coordinate species in solution, where the six-coordinate form is that of a mixed ligand complex having the formula $\left[(\mathrm{Ar})_{3} \mathrm{CorCo}(\mathrm{CN})\right.$ (DMSO) $]^{-}$, that is, where one DMSO molecule is bound trans to the $\mathrm{CN}^{-}$axial ligand. In contrast to what is seen for compounds $\mathbf{1}(\mathrm{CN})$ and $\mathbf{2}(\mathrm{CN})$, there is no spectral evidence for the binding of a solvent molecule to $3(\mathrm{CN})$, since nearly identical spectral patterns are observed in neat DMSO and $\mathrm{CH}_{2} \mathrm{Cl}_{2}$; this result definitively rules out the first of the two possibilities posed above, where a DMSO molecule would replace the bound cyanide axial ligand.

The most definitive spectroscopic evidence for a sixcoordinate cobalt corrole is given by the presence of an intense Q-band at 600-700 nm. This diagnostic criteria has been observed for numerous six-coordinate cobalt corroles with different macrocyclic substituents ${ }^{38,46,58,72,74}$ and in the present series of corroles is located from 644 to $653 \mathrm{~nm}$ for compounds $\mathbf{1}(\mathrm{CN})-\mathbf{3}(\mathrm{CN})$ when dissolved in pyridine (Figure 1c). The absorbing species present in solution is assigned to the six-coordinate mixed ligand complexes $\mathbf{1}(\mathrm{CN})(\mathrm{Py})-\mathbf{3}(\mathrm{CN})(\mathrm{Py})$, which possess a single pyridine ligand bound trans to the axial $\mathrm{CN}^{-}$ligand on the synthesized compound. Mixed-ligand cobalt(III) triarylcorroles containing one pyridine ligand and one triphenylphosphine $\left(\mathrm{PPh}_{3}\right)$ axial ligand $^{75}$ also have spectral features similar to the mixed-ligand $(\mathrm{CN})(\mathrm{Py})$ corroles.

Additional evidence for assignment of a mixed ligand complex is given by comparing wavelengths for the diagnostic Q-band of $1(\mathbf{C N})(\mathbf{P y})-3(\mathbf{C N})(\mathbf{P y})$ to that of the bis-Py derivatives, $\mathbf{1}(\mathbf{P y})_{2}-\mathbf{3}(\mathbf{P y})_{2}$, generated in situ from the monoDMSO complexes. These bis-Py complexes are formed immediately after dissolving 1(DMSO)-3(DMSO) in pyridine and possess an intense Q-band located from 624 to 631 $\mathrm{nm}$ as seen by the spectral data in Table 1 and Figure S6. Further confirmation of the assigned mixed ligand complexes is provided by the transient nature of the six-coordinate species, which is converted to the bis-Py adducts, $\mathbf{1}(\mathbf{P y})_{2}-\mathbf{3}(\mathbf{P y})_{2}$, over time. An example of this slow kinetically controlled process is given in Figure $S 7$ for $\mathbf{1}(\mathbf{C N})$. To confirm the favored formation of the mixed-ligand $(\mathrm{CN})(\mathrm{Py})$ corroles, we computed the free energies of reaction $\left(\Delta_{\mathrm{r}} G^{0}\right)$ for formation of $\mathbf{1}(\mathrm{CN})(\mathrm{Py})-\mathbf{3}(\mathrm{CN})(\mathrm{Py})$ from the corresponding ligated complexes. As shown in the Figure 2, the most stable species

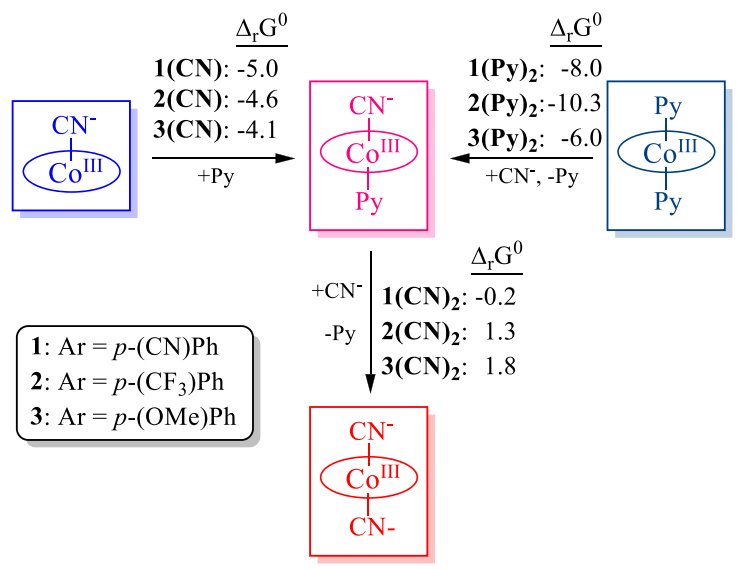

Figure 2. Free energies of reaction, $\Delta_{\mathrm{r}} G^{0}$ (in $\mathrm{kcal} / \mathrm{mol}$ ), for formation of the mixed-ligand complexes from the mono- $\mathrm{CN}$, bis-Py, and bis$\mathrm{CN}$ complexes.

among the $(\mathrm{CN}),(\mathrm{Py})_{2}$, and $(\mathrm{CN})(\mathrm{Py})$ complexes are the mixed-ligand $(\mathrm{CN})(\mathrm{Py})$ adducts for each corrole $(1-3)$. Note that, in neat pyridine, formation of the initial kinetically favorable mixed ligand species is followed by conversion to the thermodynamically stable bis-pyridine complexes due to the high concentration of the pyridine solvent as compared to $\mathrm{CN}^{-}$ligand, that is, Le Chatelier's principle. In the presence of TBACN, the bis-CN complexes are slightly stable (i.e., small $\Delta_{\mathrm{r}} G^{0}$ values) with respect to the mixed ligand adducts. It is worth pointing out that equilibrium constants are enhanced by a factor of 10 for every $1.36 \mathrm{kcal} / \mathrm{mol}$ of $\Delta_{\mathrm{r}} G^{0}$ at $298 \mathrm{~K}$ $\left(\Delta_{\mathrm{r}} G^{0}=-R T \ln K_{\mathrm{eq}}\right)$; thus, an equilibrium between the mixedligand $(\mathrm{CN})(\mathrm{Py})$ and bis- $\mathrm{CN}$ complexes in pyridine solutions containing TBACN might be expected on the basis of the small $\Delta_{\mathrm{r}} G^{0}$ values computed $(-0.2$ to $+1.8 \mathrm{kcal} / \mathrm{mol})$. This equilibrium is indeed spectroscopically observed as described in the following section.

Finally, note that all three mono- $\mathrm{CN}$ derivatives possess a near-IR band (NIR) located between 720 and $749 \mathrm{~nm}$, independent of solvent (see Table 1, Figure 1, and Table S1). This band (marked by an asterisk $(*)$ ) is assigned to a partially 
oxidized cobalt corrole complex as shown by electrochemical and spectroelectrochemical data described later in the manuscript. A similar NIR band at $716 \mathrm{~nm}$ was reported by Osuka and co-workers ${ }^{73}$ for a structurally characterized mixedligand cobalt corrole radical having one cyanide and one pyridine axial ligand, and the reported spectrum for this singly oxidized complex was compared to that of the neutral bis-Py corrole.

UV-Visible Spectra of Bis-CN Derivatives. Our previous report on anion interaction with cobalt corroles identified a bis- $\mathrm{CN}$ adduct generated in situ from $(\mathrm{Ar})_{3} \mathrm{CorCo}-$ (DMSO) after addition of TBACN in $\mathrm{CH}_{2} \mathrm{Cl}_{2}$ solutions. ${ }^{47}$ Bis$\mathrm{CN}$ products were also obtained in the current study by titrating the synthesized mono- $\mathrm{CN}$ compounds with TBACN, and examples of the spectral changes during this ligand addition reaction are given in Figure 3 for $\mathbf{1}(\mathrm{CN})$ and $2(\mathrm{CN})$.
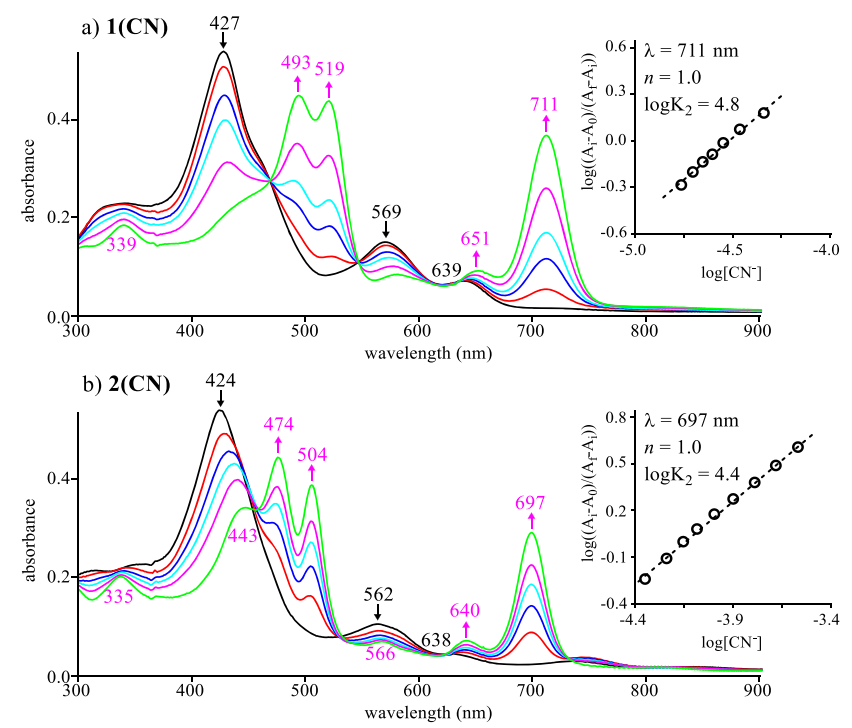

Figure 3. UV-Vis titration of cpd $\mathbf{1}(\mathrm{CN})$ and $\mathbf{2}(\mathrm{CN})$ with TBACN in DMSO to give $\mathbf{1}(\mathrm{CN})_{2}$ and $\mathbf{2}(\mathrm{CN})_{2}$, respectively.

The spectral changes for a $\mathrm{CN}^{-}$titration of $3(\mathrm{CN})$ under the same solution conditions is given in Figure S8. The Hill plots are shown as inserts in the figures, and each has a slope of $n=$ 1.0 , indicating the addition of one $\mathrm{CN}^{-}$ligand as given in eq 4 . The Hill plots in Figures 3 and S8 along with the presence of three clear isosbestic points in each titration indicate the lack of spectroscopically detectable intermediates in the titration. Thus, the data in Figure 3 are consistent with a previously reported spectroscopically monitored $\mathrm{CN}^{-}$titration of $\left(\mathrm{F}_{5} \mathrm{Ph}\right)_{3} \mathrm{CorCo}(\mathrm{DMSO})$ to give the bis-CN corrole in $\mathrm{CH}_{2} \mathrm{Cl}_{2}$. The measured formation constants $\left(\log K_{2}\right.$ ) for the addition of a single $\mathrm{CN}^{-}$ligand to the five-coordinate mono$\mathrm{CN}$ derivatives of $\mathbf{1}(\mathrm{CN})-\mathbf{3}(\mathrm{CN})$ range from $\log K_{2}=2.8$ to 4.8 in DMSO. These experimental $\log K_{2}$ values are summarized in Table 2 along with the computationally determined formation constants. Both methods provide values with similar systematic trends, where the largest $\log K_{2}$ value is obtained for the most electron-withdrawing complex, $\mathbf{1}(\mathrm{CN})$, while a smaller formation constant is seen for $3(\mathrm{CN})$, which possesses electron-donating $p$-methoxyphenyl substituents.

The UV-visible spectra of $\mathbf{1}(\mathrm{CN})_{2}-\mathbf{3}(\mathrm{CN})_{2}$ in $\mathrm{CH}_{2} \mathrm{Cl}_{2}$ or DMSO containing 0.1 M TBACN are shown in Figures $4 \mathrm{a}, \mathrm{b}$ and are characterized by an intense Q-band at 693-711 nm.
Table 2. Binding Constants for Addition of a Second $\mathrm{CN}^{-}$ Axial Ligand to the Mono-CN Cobalt Corroles in DMSO As Given in eq 4.

\begin{tabular}{rccc} 
& & \multicolumn{2}{c}{$\log K_{2}$} \\
\cline { 3 - 4 } $3 \sigma^{a}$ & compound & $\operatorname{expt}^{b}$ & theor $^{c}$ \\
1.98 & $\mathbf{1}(\mathrm{CN})$ & 4.8 & 5.6 \\
1.62 & $2(\mathrm{CN})$ & 4.4 & 5.3 \\
-0.81 & $3(\mathrm{CN})$ & 2.8 & 4.1
\end{tabular}

${ }^{a}$ Hammett values taken from ref $76 .{ }^{b}$ Obtained from spectroscopic titration using Hill plot (see text, Figure 2, and Figure S8). ${ }^{c}$ Theoretical values (see Experimental Section for computational details).

The presence of this band is consistent with spectra reported for other numerous bis-ligated cobalt corroles with $\mathrm{N}$-donor ligands. ${ }^{38,46,58,72,74}$ However, the diagnostic Q-band of the bis$\mathrm{CN}$ derivatives, as well as all other absorption bands of these corroles, are red-shifted by $30-50 \mathrm{~nm}$ as compared to the corresponding bis-Py adducts, whose spectra are shown in Figure S6 and the data summarized in Table 1. A more complicated spectral pattern of the bis- $\mathrm{CN}$ adducts is observed in pyridine (Figure 4c), where two relatively intense Q-bands are present between 644 and $718 \mathrm{~nm}$. The higher-energy Qband located from 655 to $644 \mathrm{~nm}$ in this solvent is assigned to the mixed ligand species $\mathbf{1}(\mathbf{C N})(\mathbf{P y})-\mathbf{3}(\mathbf{C N})(\mathbf{P y})$ as evident by a comparison of the wavelengths in the $\mathrm{Q}$-band region for compounds in the two series, namely, $653-655 \mathrm{~nm}$ for 1, 644 for 2, and 647-648 for 3 (see Table 1 and Figure 1c). The lower-energy Q-band located at 718-701 $\mathrm{nm}$ is assigned to the bis- $\mathrm{CN}$ derivatives in solution. Moreover, the ratio of the highenergy over the low-energy Q-bands varies from 2.22 to 1.80 to 0.53 for bis- $\mathrm{CN}$ adducts of the corroles $1-3$, respectively. These ratios values correlate well $\left(R^{2}=0.985\right)$ with the Hammett substituent constants $(3 \sigma)$ (see Table 2) of the meso-phenyl substituents (see Figure S9).

Electrochemistry. The electrochemical behavior of 1(DMSO)-3(DMSO), $\mathbf{1}(\mathrm{CN})-\mathbf{3}(\mathrm{CN})$, and $\mathbf{1}(\mathrm{CN})_{2}-$ $3(\mathrm{CN})_{2}$ was examined in $\mathrm{CH}_{2} \mathrm{Cl}_{2}$ and DMSO containing 0.1 $M$ TBAP. Redox properties of $\mathbf{1}(\mathrm{CN})(\mathbf{P y})-\mathbf{3}(\mathrm{CN})(\mathbf{P y})$, $\mathbf{1}(\mathrm{Py})_{2}-\mathbf{3}(\mathrm{Py})_{2}$, and $\mathbf{1}(\mathrm{CN})_{2}-\mathbf{3}(\mathrm{CN})_{2}$ were also investigated in pyridine containing $0.1 \mathrm{M}$ TBAP. As will be shown, the halfwave potentials for both oxidation and reduction vary in a predictable fashion with change in axial coordination, a factor that has been demonstrated to alter the site of electron transfer and electronic configuration of the redox-active form of the corrole in solution, that is, ligand innocence or noninnocence. $^{38,46}$

Redox Reactions in $\mathrm{CH}_{2} \mathrm{Cl}_{2}$ and DMSO Containing $0.1 \mathrm{M}$ TBAP. Examples of the cyclic voltammograms for the monoDMSO, mono- $\mathrm{CN}$, and bis- $\mathrm{CN}$ corroles 1 and 3 in DMSO containing 0.1 M TBAP are shown in Figure 5, and a summary of the measured half-wave and peak potentials in DMSO and $\mathrm{CH}_{2} \mathrm{Cl}_{2}$ is given in Table 3. Voltammograms for all three corroles in $\mathrm{CH}_{2} \mathrm{Cl}_{2} / \mathrm{TBAP}$ and compound 2 in DMSO/TBAP before and after the addition of TBACN are illustrated in Figures S10-S13.

Each corrole in Figure 5 is characterized by a reversible oneelectron oxidation and two major reductions within the DMSO solvent potential limit. The first reversible reduction of 1(DMSO)-3(DMSO) is facile $\left(E_{1 / 2}=-0.03\right.$ to $\left.-0.41 \mathrm{~V}\right)$ in both $\mathrm{DMSO}$ and $\mathrm{CH}_{2} \mathrm{Cl}_{2}$ (see Table 1) and proceeds according to eq $6 \mathrm{a}$, where electron addition is assigned to 

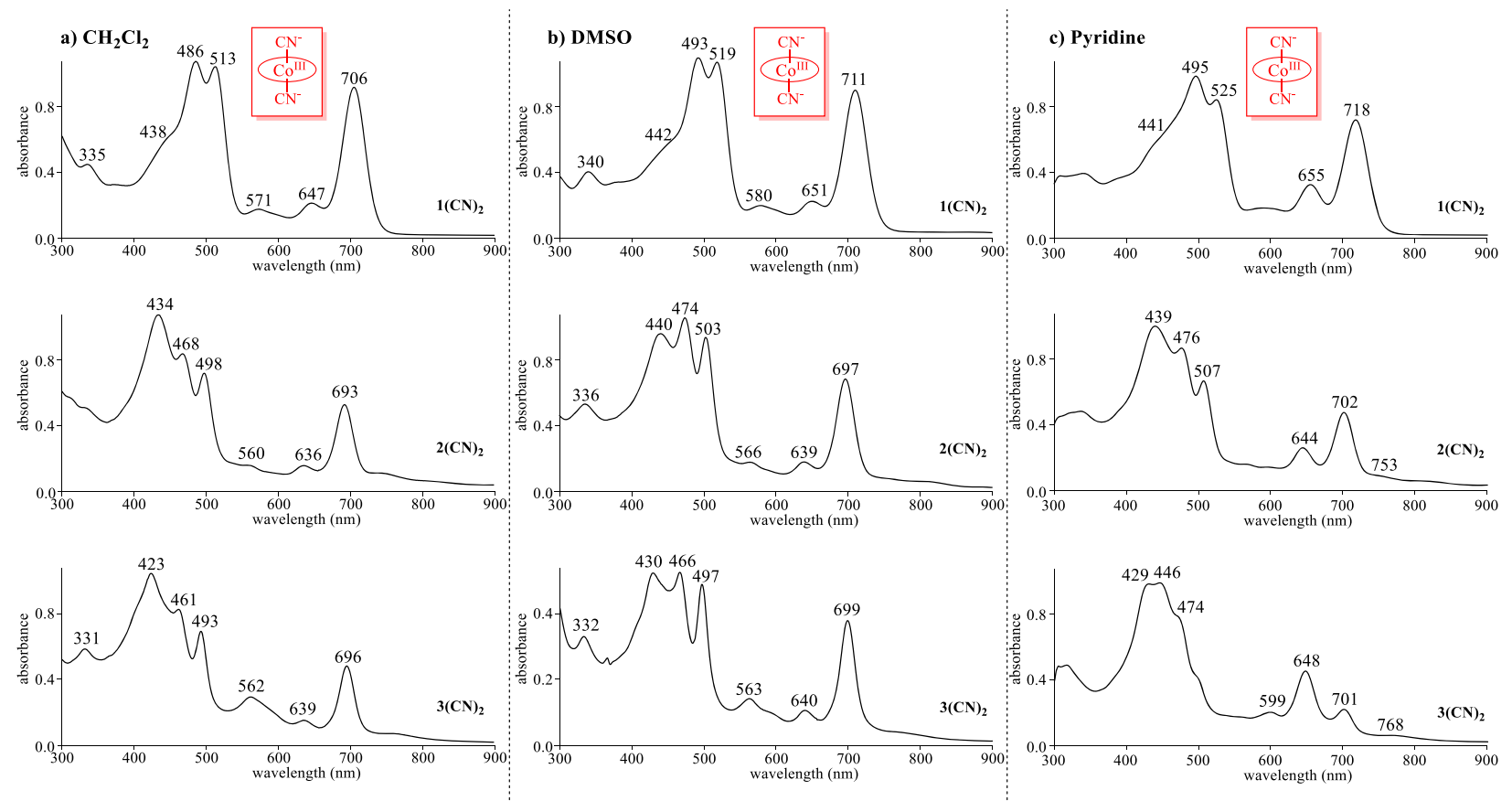

Figure 4. $\mathrm{UV}-\mathrm{Vis}$ spectra at $\sim 10^{-5} \mathrm{M}$ of the bis-CN adducts in (a) $\mathrm{CH}_{2} \mathrm{Cl}_{2}$, (b) DMSO, and (c) pyridine all containing $0.05 \mathrm{M}$ TBACN.

occur at the conjugated macrocycle and the singly reduced $\mathrm{Co}$ (II) form of the corrole is four coordinate. ${ }^{45,47}$ In contrast to this facile and reversible reduction, the first reduction of $\mathbf{1}(\mathbf{C N})-\mathbf{3}(\mathbf{C N})$ is irreversible and negatively shifted in potential by nearly $1.0 \mathrm{~V}$ in DMSO or $\mathrm{CH}_{2} \mathrm{Cl}_{2}$. The cathodic peak potential of this irreversible reduction is located at $E_{\mathrm{pc}}=$ -1.14 to -1.32 in $\mathrm{CH}_{2} \mathrm{Cl}_{2}$ or $E_{\mathrm{pc}}=-1.09$ to $-1.31 \mathrm{~V}$ in DMSO (see Table 1) and is coupled to an anodic reoxidation peak at a potential close to that of the mono-DMSO adduct in the same solvent for a scan rate of $0.1 \mathrm{~V} / \mathrm{s}$ (see Figure 5). The $E_{\mathrm{pa}}$ of the reoxidation is located at $-0.11 \mathrm{~V}$ for $\mathbf{1}(\mathrm{CN})$ and $-0.31 \mathrm{~V}$ for $3(\mathbf{C N})$. This electrochemical behavior is consistent with a one-electron reduction at the central metal ion followed by a rapid dissociation of the axial ligand to give the four-coordinate $\mathrm{Co}$ (II) corrole product (see eq 6b). A subsequent reversible reduction of the electrogenerated fourcoordinate cobalt corrole product of eq $6 \mathrm{a}$ and $6 \mathrm{~b}$ is described by eq 7 . The metal oxidation state of the electrogenerated species was not assigned, but $E_{1 / 2}$ for this process is located at essentially identical potentials for the mono-DMSO and mono$\mathrm{CN}$ adducts, indicating the same electrogenerated product is present in each case; that is, $E_{1 / 2}=-1.41$ to $-1.40 \mathrm{~V}$ for $\mathbf{1}$ (DMSO) and $\mathbf{1}(\mathrm{CN})$, and $E_{1 / 2}=-1.59$ to $-1.60 \mathrm{~V}$ for 3(DMSO) and 3(CN).

$$
\begin{aligned}
(\mathrm{Ar})_{3} \mathrm{Cor}^{\bullet} \mathrm{Co}^{\mathrm{II}}(\mathrm{DMSO}) & +\mathrm{e}^{-} \\
\rightleftharpoons\left[(\mathrm{Ar})_{3} \mathrm{CorCo}^{\mathrm{II}}\right]^{-} & +\mathrm{DMSO} \\
{\left[(\mathrm{Ar})_{3} \mathrm{CorCo}^{\mathrm{III}}(\mathrm{CN})\right]^{-} } & +\mathrm{e}^{-} \rightleftharpoons\left[(\mathrm{Ar})_{3} \mathrm{CorCo}^{\mathrm{II}}(\mathrm{CN})\right]^{2-} \\
& \rightarrow\left[(\mathrm{Ar})_{3} \mathrm{CorCo}^{\mathrm{II}}\right]^{-}+\mathrm{CN}^{-} \\
{\left[(\mathrm{Ar})_{3} \mathrm{CorCo}^{\mathrm{II}}\right]^{-}+\mathrm{e}^{-} } & \rightleftharpoons\left[(\mathrm{Ar})_{3} \mathrm{CorCo}^{2-}\right.
\end{aligned}
$$

Equations $6 \mathrm{a}, 6 \mathrm{~b}$, and 7 also describe the reactions in $\mathrm{CH}_{2} \mathrm{Cl}_{2}$, but the reduction, as expressed in eq 7, is irreversible due to a homogeneous chemical reaction of $\left[(\mathrm{Ar})_{3} \mathrm{CorCo}^{\mathrm{II}}\right]^{-}$ with the solvent following electron transfer ${ }^{77-80}$ (see Figures
S11-S13). However, the same peak potentials are again observed for each corrole in the two series with a given $\mathrm{Ar}$ group $\left(E_{\mathrm{pc}}=-1.49\right.$ to $-1.48 \mathrm{~V}$ for $\mathbf{1}(\mathrm{DMSO})$ or $\mathbf{1}(\mathrm{CN})$, -1.54 to $-1.52 \mathrm{~V}$ for $2(\mathrm{DMSO})$ or $2(\mathrm{CN})$, and -1.66 to $-1.67 \mathrm{~V}$ for $3(\mathrm{DMSO})$ or $3(\mathrm{CN}))$. The significant difference in electrochemical behavior between the five-coordinate $\mathrm{CN}$ and five-coordinate DMSO complexes arises from a difference in the initial redox-active species; that is, the mono-DMSO cobalt corroles are assigned as containing a $\mathrm{Co}^{\mathrm{II}}$ central metal ion and a noninnocent macrocycle ligand in its cation radical form $\left(\mathrm{Cor}^{\bullet 2-}\right),{ }^{45,47}$ while the mono-CN derivatives are assigned as containing a $\mathrm{Co}^{\mathrm{III}}$ central metal ion and an innocent trivalent macrocycle $\left(\mathrm{Cor}^{3-}\right)$. This latter assignment is analogous to what was previously reported for the bis-Py cobalt corrole complexes. ${ }^{38,46}$ Following the work of Ghosh $^{38,81}$ and others, ${ }^{82}$ we used DFT calculations to investigate the ligand noninnocence in the five-coordinate DMSO complexes. The ground state of the three 1(DMSO), 2(DMSO), and 3(DMSO) complexes is an open-shell system in which a $\mathrm{Co}$ (II) center is antiferromagnetically coupled to a radical corrole, in full support of the $(\mathrm{Ar})_{3} \mathrm{Cor}^{\bullet} \mathrm{Co}^{\mathrm{II}}(\mathrm{DMSO})$ structure, as shown by the spin density of the complex (Figure 6 for 1(DMSO) and Figure S14 for 2(DMSO) and 3(DMSO). As expected for five-coordinate corroles, the coupling occurs with the $\mathrm{d}_{z}{ }^{2}$ orbital of the cobalt and a $\pi$ orbital of the corrole. $^{38}$ The triplet state is located only $0.2 \mathrm{kcal} / \mathrm{mol}$ ( $7 \mathrm{meV}$ ) above the singlet ground state and corresponds to an intermediate spin state in which all the spin density is on the cobalt $\mathrm{d}_{x z}$ and $\mathrm{d}_{z^{2}}$ orbitals.

In agreement with the spectroscopic data described in Figures 3 and 4, formation of the bis- $\mathrm{CN}$ adduct also occurs under the electrochemical conditions in the presence of TBACN. Reduction of the in situ generated $\mathbf{1}(\mathrm{CN})_{2}-3(\mathrm{CN})_{2}$ complexes in DMSO, located at $E_{\mathrm{pc}}=-1.71$ to $-1.63 \mathrm{~V}$ (see Figure 5 and Table 3), is the most thermodynamically difficult electron addition (most negative potential) to any cobalt corrole reported and demonstrates the enhanced ability of the 

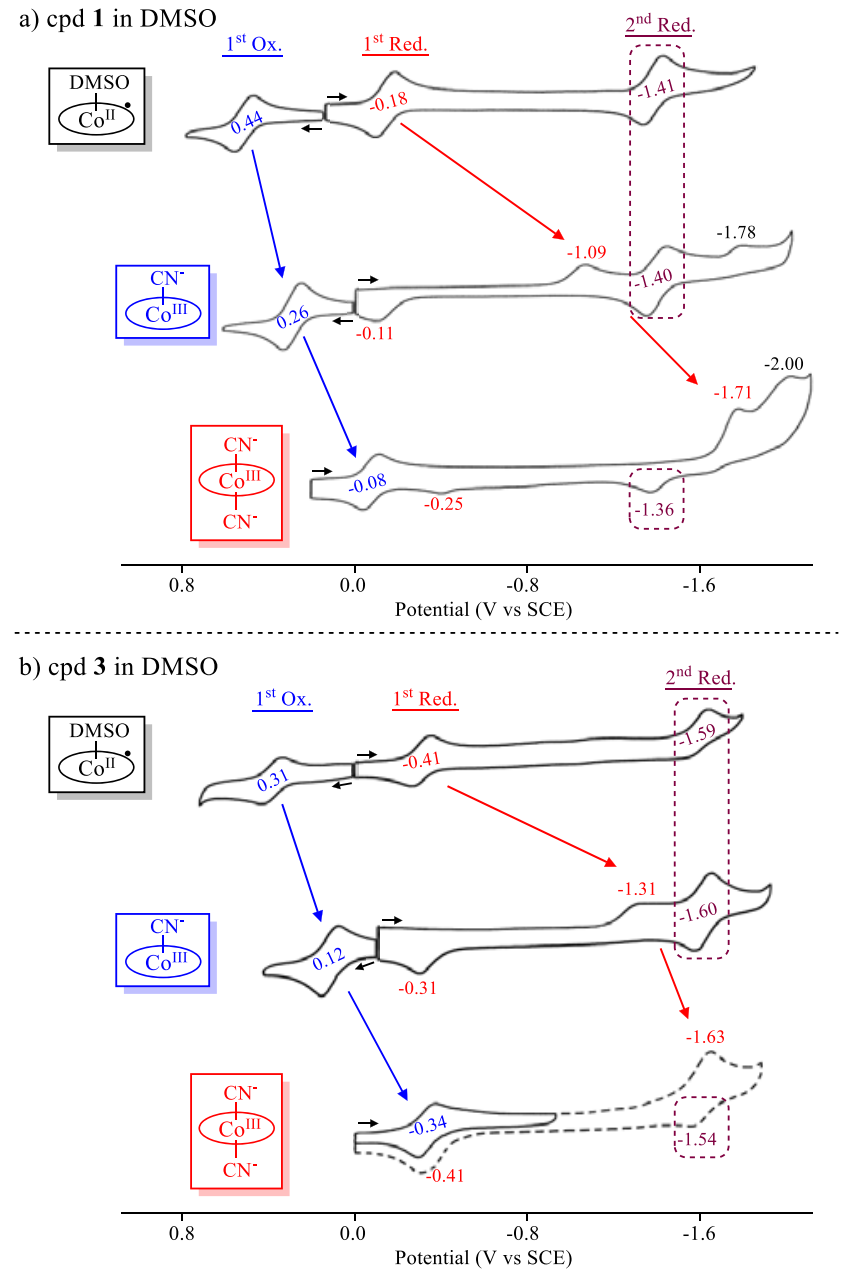

Figure 5. Cyclic voltammograms at $10^{-3} \mathrm{M}$ of (a) 1 (DMSO) and $\mathbf{1}(\mathrm{CN})_{n}$ and (b) 3 (DMSO) and $3(\mathrm{CN})_{n}$, where $n=1$ or 2 in DMSO containing $0.1 \mathrm{M}$ TBAP. The bis-CN adduct $(n=2)$ was generated in solutions containing 200 equiv of TBACN. Scan rate $=0.1 \mathrm{~V} / \mathrm{s}$. The $\left[(\mathrm{Ar})_{3} \mathrm{CorCo}\right]^{-} /\left[(\mathrm{Ar})_{3} \mathrm{CorCo}\right]^{2-}$ process is boxed for clarity (see text). Potentials for the first reduction and first oxidation are shown in red and blue, while shifts of the redox potentials for these processes are indicated by red and blue arrows, respectively.

$\mathrm{CN}^{-}$axial ligands to stabilize the higher-valent forms of the cobalt central metal ion. This reduction involves an overall stepwise two-electron conversion of $\left[(\mathrm{Ar})_{3} \mathrm{CorCo}^{\mathrm{III}}(\mathrm{CN})_{2}\right]^{2-}$ to $\left[(\mathrm{Ar})_{3} \mathrm{CorCo}^{\mathrm{II}}\right]^{2-}$ via an electrochemical, chemical, electrochemical (ECE) mechanism proceeding first through eq 8 to generate the four-coordinate $\mathrm{Co}$ (II) corrole with an unreduced macrocycle followed by a rapid second one-electron addition, giving the same doubly reduced four-coordinate cobalt corrole product as seen in eq 7 .

$$
\begin{aligned}
{\left[(\mathrm{Ar})_{3} \mathrm{CorCo}^{\mathrm{III}}(\mathrm{CN})_{2}\right]^{2-} } & +\mathrm{e}^{-} \rightleftharpoons\left[(\mathrm{Ar})_{3} \mathrm{CorCo}^{\mathrm{II}}(\mathrm{CN})_{2}\right]^{3-} \\
& \rightarrow\left[(\mathrm{Ar})_{3} \mathrm{CorCo}^{\mathrm{II}}\right]^{-}+2 \mathrm{CN}^{-}
\end{aligned}
$$

Additional evidence for formation of the doubly reduced four-coordinate corrole, $\left[(\mathrm{Ar})_{3} \mathrm{CorCo}\right]^{2-}$, is given by the appearance of an anodic peak on the reverse scan, which is located at the same potential as for reoxidation of the mono$\mathrm{CN}$ or mono-DMSO derivatives. This is evident in the cyclic voltammograms of Figures 5a, where anodic peak potentials for reoxidation are located at $E_{\mathrm{pa}}=-1.37,-1.37$, and -1.36 for
$\mathbf{1}(\mathrm{DMSO}), \mathbf{1}(\mathrm{CN})$, and $\mathbf{1}(\mathrm{CN})_{2}$, respectively, and are assigned in each case to the $\left[(\mathrm{Ar})_{3} \mathrm{CorCo}^{\mathrm{II}}\right]^{-} /\left[(\mathrm{Ar})_{3} \mathrm{CorCo}^{\mathrm{II}}\right]^{2-}$ redox process. Similar potentials are observed for the other two corrole systems (see Figure $5 \mathrm{~b}$ and S11). Moreover, the ratio of peak current for reduction of the bis-CN complexes at $E_{\mathrm{pc}}=$ -1.71 to $-1.63 \mathrm{~V}$ in DMSO over that for the first oxidation at $E_{1 / 2}=-0.08$ to $-0.34 \mathrm{~V}$ ranges from 2.04 to 2.10 for $1(\mathrm{CN})_{2}-$ $3(\mathbf{C N})_{2}$ (see Figures 5 and S10), consistent with an overall two-electron transfer ECE mechanism.

Of the investigated corroles, the mono-DMSO complexes 1(DMSO)-3(DMSO) are the most difficult to oxidize, $E_{1 / 2}=$ 0.72 to $0.57 \mathrm{~V}$ in $\mathrm{CH}_{2} \mathrm{Cl}_{2}$ and $E_{1 / 2}=0.44$ to $0.31 \mathrm{~V}$ in DMSO, while the bis- $\mathrm{CN}$ derivatives undergo the most-facile oxidation reported of any cobalt corrole examined, with $E_{1 / 2}$ ranging from -0.19 to $-0.45 \mathrm{~V}$ for $1(\mathrm{CN})_{2}-3(\mathrm{CN})_{2}$ in $\mathrm{CH}_{2} \mathrm{Cl}_{2}$ and from -0.08 to $-0.34 \mathrm{~V}$ for the same compounds in DMSO (see Table 3). The significant cathodic shift in $E_{1 / 2}$ upon going from the mono-DMSO to the mono- $\mathrm{CN}$ and then to the bis$\mathrm{CN}$ adducts in a given series of corroles with a specific $\mathrm{Ar}$ group is a result of (i) the addition of a strongly nucleophilic $\mathrm{CN}^{-}$ligand(s), which stabilize the high-valent cobalt(III) form of the corrole while shifting the corrole ligand from noninnocent in the case of the mono-DMSO adducts to innocent in the case of the mono- and bis- $\mathrm{CN}$ derivatives, and (ii) the increased negative charge on the molecule due to binding of the anionic cyanide ligands. These oxidation processes are described by eqs $9-11$ and give a $\mathrm{Co}$ (III) corrole $\pi$-cation radical. This assignment is supported in large part by data in the literature, ${ }^{16,46,73,74,77}$ which has demonstrated the ability of singly oxidized cobalt corroles to strongly coordinate two axial ligands. Moreover a characterization of $\left[(\mathrm{Ar})_{3} \mathrm{Cor}^{\bullet} \mathrm{Co}^{\mathrm{III}}(\mathrm{DMSO})_{2}\right]^{+}$and $\left[(\mathrm{Ar})_{3} \mathrm{Cor}^{\bullet} \mathrm{Co}^{\mathrm{III}}(\mathrm{CN})_{2}\right]^{-}$as cobalt(III) cation radical products of eq 9 and 11 , respectively, has been described in detail for related compounds. $45,47,73$ Thus, a bis-ligated $\mathrm{Co}$ (III) $\pi$-cation radical oxidation product is also assigned in eq 10 on the basis of the easier oxidation potential in DMSO as compared to $\mathrm{CH}_{2} \mathrm{Cl}_{2}$, the known coordination chemistry of oxidized cobalt corroles, and the spectroelectrochemical data given in Figure 7.

$$
\begin{aligned}
& (\mathrm{Ar})_{3} \mathrm{Cor}^{\bullet} \mathrm{Co}^{\mathrm{II}}(\mathrm{DMSO})+\mathrm{DMSO} \\
& \rightleftharpoons\left[(\mathrm{Ar})_{3} \mathrm{Cor}^{\bullet} \mathrm{Co}^{\mathrm{III}}(\mathrm{DMSO})_{2}\right]^{+}+\mathrm{e}^{-} \\
& {\left[(\mathrm{Ar})_{3} \mathrm{CorCo}^{\mathrm{III}}(\mathrm{CN})\right]^{-}+\mathrm{DMSO}} \\
& \rightleftharpoons\left[(\mathrm{Ar})_{3} \mathrm{Cor}^{\bullet} \mathrm{Co}^{\mathrm{III}}(\mathrm{CN})(\mathrm{DMSO})\right]^{0}+\mathrm{e}^{-} \\
& {\left[(\mathrm{Ar})_{3} \mathrm{CorCo}^{\mathrm{III}}(\mathrm{CN})_{2}\right]^{2-}} \\
& \quad \rightleftharpoons\left[(\mathrm{Ar})_{3} \mathrm{Cor}^{\bullet} \mathrm{Co}{ }^{\mathrm{III}}(\mathrm{CN})_{2}\right]^{-}+\mathrm{e}^{-}
\end{aligned}
$$

Each one-electron oxidation product of 2 in Figure 7 is characterized by a major band in the Soret region at $426-435$ $\mathrm{nm}$ and a less intense near-IR (NIR) band located at $703 \mathrm{~nm}$ for 2(DMSO), $719 \mathrm{~nm} 2(\mathrm{CN})$, and 745 for $2(\mathrm{CN})_{2}$, the latter being a distinct spectral feature of the cobalt(III) corrole $\pi$-cation radical. ${ }^{16,73}$ These bands are indicated by an asterisk (*) in Figure 7 and located at a wavelength that varies linearly with the charge from +1 to -1 on the singly oxidized products as shown in eqs $9-11$ and plotted in Figure 8. NIR bands between 706 and $760 \mathrm{~nm}$ are observed for the other singly oxidized corroles in DMSO (Table 4 and Figures S15-S18), and the fact that an identical linear relationship is observed between the wavenumber of the NIR band and the charge of 
Table 3. Half-Wave of Peak Potentials $\left(E_{1 / 2}\right.$ or $E_{\mathrm{p}}$ vs SCE) of the Investigated Compounds in $\mathrm{DMSO}^{\text {or }} \mathrm{Ch}_{2} \mathrm{Cl}_{2} \mathrm{Solvents}$ Containing 0.1 M TBAP with and without Added TBACN

\begin{tabular}{|c|c|c|c|c|c|c|}
\hline & & & & otential & & \\
\hline & & & & & reduction & \\
\hline & & & & & & \\
\hline solution condition & cpd & 2 nd & 1 st & $E_{1 / 2}$ & $E_{\mathrm{pc}}\left(E_{\mathrm{pa}}\right)$ & 2nd \\
\hline DMSO & 1(DMSO) & $0.90^{a}$ & 0.44 & -0.18 & & -1.41 \\
\hline & 2(DMSO) & $0.87^{a}$ & 0.39 & -0.25 & & -1.51 \\
\hline & 3(DMSO) & 0.68 & 0.31 & -0.41 & & -1.59 \\
\hline & $1(\mathrm{CN})$ & & 0.26 & & $-1.09(-0.11)$ & -1.40 \\
\hline & $2(\mathrm{CN})$ & & 0.22 & & $-1.14(-0.22)$ & -1.50 \\
\hline & $3(\mathrm{CN})$ & & 0.12 & & $-1.31(-0.31)$ & -1.60 \\
\hline DMSO + TBACN & $1(\mathrm{CN})_{2}$ & & -0.08 & & $-1.71^{b}(-0.25)$ & $-1.71^{b}$ \\
\hline & $2(\mathrm{CN})_{2}$ & & -0.13 & & $-1.67^{b}(-0.47)$ & $-1.67^{b}$ \\
\hline & $3(\mathrm{CN})_{2}$ & & -0.34 & & $-1.63^{b}(-0.41)$ & $-1.63^{b}$ \\
\hline $\mathrm{CH}_{2} \mathrm{Cl}_{2}$ & 1(DMSO) & 0.89 & 0.72 & -0.03 & & $-1.49^{a}$ \\
\hline & 2(DMSO) & 0.88 & 0.70 & -0.04 & & $-1.54^{a}$ \\
\hline & 3(DMSO) & 0.79 & 0.57 & -0.18 & & $-1.66^{a}$ \\
\hline & $1(\mathrm{CN})$ & & $0.42^{a}$ & & $-1.14^{a}(-0.16)$ & $-1.48^{a}$ \\
\hline & $2(\mathrm{CN})$ & & 0.32 & & $-1.19^{a}(-0.19)$ & $-1.52^{a}$ \\
\hline & $3(\mathrm{CN})$ & & 0.22 & & $-1.32^{a}(-0.14)$ & $-1.67^{a}$ \\
\hline $\mathrm{CH}_{2} \mathrm{Cl}_{2}+\mathrm{TBACN}$ & $1(\mathrm{CN})_{2}$ & & -0.19 & & & \\
\hline & $2(\mathrm{CN})_{2}$ & & -0.25 & & & \\
\hline & $3(\mathrm{CN})_{2}$ & & -0.45 & & & \\
\hline
\end{tabular}

${ }^{a}$ Irreversible peak potential at a scan rate of $0.1 \mathrm{~V} / \mathrm{s} .{ }^{b}$ Overlapping and irreversible two-electron process.

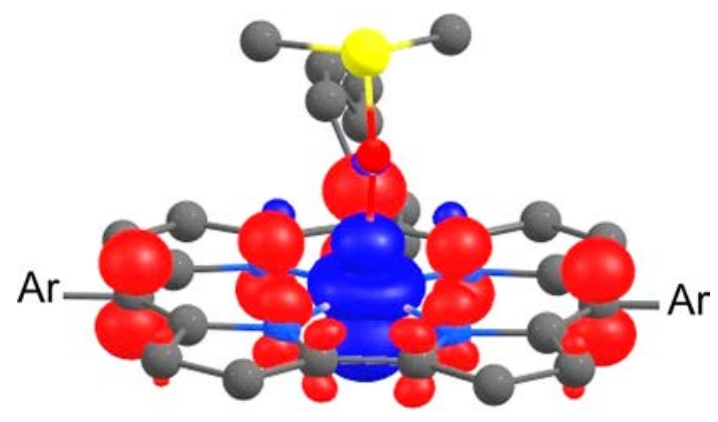

Figure 6. Spin density of the broken symmetry singlet for 1(DMSO) (contour $0.005 \mathrm{e} / \AA^{3}$ ). Spin-up density is shown in blue (and corresponds to the cobalt $\mathrm{d}_{z^{2}}$ orbital), while spin-down density is shown in red (and is localized on the corrole moiety).

the singly oxidized corrole in each series (Figure S18) demonstrates clearly that the shift of the band stems only from the charge on the corrole and not from the type of substituent.

Finally, note that the $719 \mathrm{~nm}$ NIR band of singly oxidized 2(CN) in Figure $7 \mathrm{~b}$ is located at essentially the same wavelength as a $720 \mathrm{~nm}$ NIR band for the neutral compound in Figure $1 \mathrm{~b}$. The NIR bands of the other oxidized corroles, $\mathbf{1}(\mathbf{C N})$ and $3(\mathbf{C N})$, (Table 4) also match wavelengths of bands for the corresponding neutral complexes under the same solution conditions (Table 1), thus further confirming the presence of a partially oxidized corrole when the synthesized mono-CN derivatives are dissolved in solution.

In summary, a self-consistent electron-transfer mechanism of the mono-DMSO, mono- $\mathrm{CN}$, and bis- $\mathrm{CN}$ adducts in DMSO is shown in Scheme 2, which includes the measured potentials for $\mathbf{1}(\mathrm{DMSO}), \mathbf{1}(\mathrm{CN})$, and $\mathbf{1}(\mathrm{CN})_{2}$. Potentials for the other compounds are given in Table 3 . All three ligated forms of the corrole in Scheme 2 are characterized by two reductions, the first of which is followed by a loss of axial ligand to give a fourcoordinate $\mathrm{Co}$ (II) corrole product. This reaction occurs from -0.18 to $-1.71 \mathrm{~V}$ in the case of $\mathbf{1}(\mathrm{DMSO}), \mathbf{1}(\mathrm{CN})$, and $\mathbf{1}(\mathrm{CN})_{2}$. A further reduction then occurs at more negative potentials to give the formal $\mathrm{Co}(\mathrm{I})$ corrole product, $\left[(\mathrm{Ar})_{3} \mathrm{CorCo}\right]^{2-}$, the metal oxidation state being suggested by the chemical reactivity of the reduced corrole with $\mathrm{CH}_{2} \mathrm{Cl}_{2}$, a property of the $\mathrm{Co}(\mathrm{I})$ oxidation state in related macrocycles. $^{77-80}$ This reduction is located at $-1.40 \mathrm{~V}$ for the $p$ $\mathrm{CNPh}$ derivatives (Scheme 2) and at $-1.59 /-1.60 \mathrm{~V}$ for the $p$ $\mathrm{OMePh}$ compounds (Figure 5). Finally, the one-electron oxidation of each corrole leads to a six-coordinate $\mathrm{Co}$ (III) $\pi$ cation radical product as supported by the electrochemical and spectroelectrochemical data outlined above.

Electrochemistry in Pyridine Containing 0.1 M TBAP. The nine corroles spectroscopically characterized in Figures $1 \mathrm{c}, 4 \mathrm{c}$, and $\mathrm{S} 7$ corresponding to the bis- $\mathrm{CN}$, bis-Py, and mixed ligand $(\mathrm{CN})(\mathrm{Py})$ adducts were investigated as to their electrochemistry in pyridine containing 0.1 M TBAP. Examples of cyclic voltammograms for oxidation and reduction are shown in Figures 9 and 11 for $\mathbf{1}(\mathbf{P y})_{2}, \mathbf{1}(\mathbf{C N})(\mathbf{P y})$, and $\mathbf{1}(\mathbf{C N})_{2}$, while a summary of the measured half-wave and peak potentials for all of the compounds is given in Table 5. Similar voltammograms for the other corroles in pyridine, 0.1 M TBAP are illustrated in Figures S19-S22.

Each bis-ligated corrole in pyridine is characterized by a reversible one-electron oxidation within the solvent potential window. The $E_{1 / 2}$ values for $\mathbf{1}(\mathbf{P y})_{2}-\mathbf{3}(\mathbf{P y})_{2}$ range from 0.47 to $0.23 \mathrm{~V}$ (Table 5) and proceed according to eq 12, where electron abstraction is assigned to occur at the conjugated macrocycle on the basis of previously characterized bis-Py cobalt corroles. ${ }^{46}$ More facile oxidations of the mixed ligand $\left(E_{1 / 2}=0.17\right.$ to $\left.-0.07 \mathrm{~V}\right)$ and bis-CN derivatives $\left(E_{1 / 2}=-0.20\right.$ to $-0.43 \mathrm{~V}$ ) are seen for compounds $1-3$, and these reactions occur as shown in eqs 13 and 11 , where both the initial and 

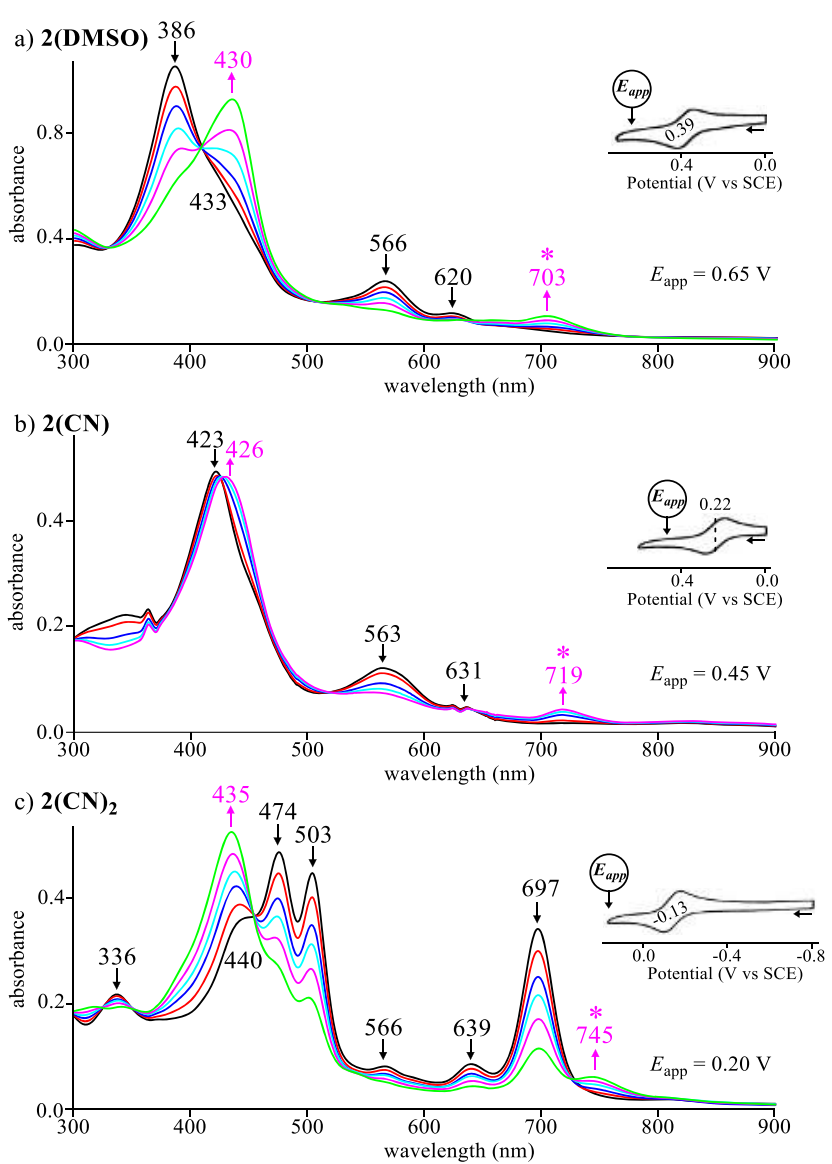

Figure 7. Spectral changes associated with the oxidative conversion of (a) 2(DMSO), (b) $2(\mathrm{CN})$, and (c) $2(\mathrm{CN})_{2}$ in DMSO containing 0.1 $\mathrm{M}$ TBAP. The bis-CN adduct $\left(\mathbf{2}(\mathbf{C N})_{2}\right)$ was generated in solutions containing 200 equiv of TBACN. The NIR band marked with an asterisk $(*)$ is indicative of the cobalt corrole radical. (insets) Cyclic voltammograms under these solution conditions.

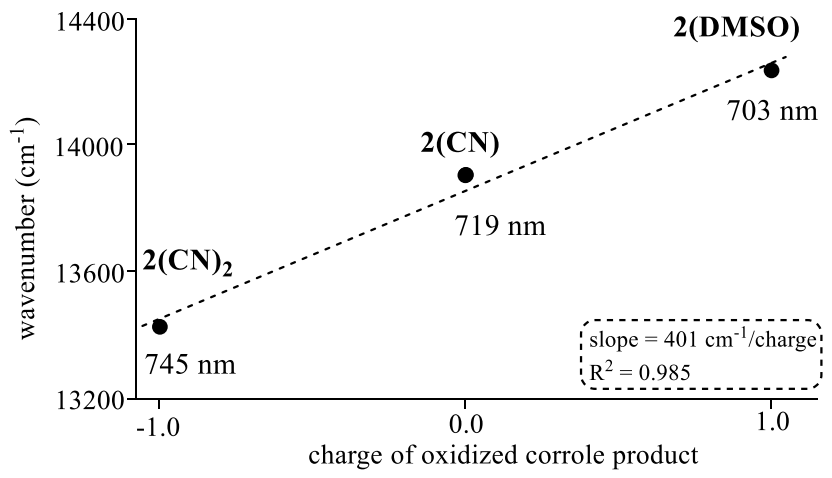

Figure 8. Plot of wavenumber $\left(\mathrm{cm}^{-1}\right)$ of the NIR band of the singly oxidized corrole vs charge of the oxidized corrole product corrrole for the mono-DMSO, mono-CN, and bis-CN adducts in DMSO containing $0.1 \mathrm{M}$ TBAP.

final forms of the corrole are six-coordinate. Note that eq 11 below describes the oxidation of the bis-CN adduct in DMSO and in pyridine solutions.

$$
\begin{aligned}
& (\mathrm{Ar})_{3} \mathrm{CorCo}^{\mathrm{III}}(\mathrm{Py})_{2} \rightleftharpoons\left[(\mathrm{Ar})_{3} \mathrm{Cor}^{\bullet} \mathrm{Co}^{\mathrm{III}}(\mathrm{Py})_{2}\right]^{+}+\mathrm{e}^{-} \\
& {\left[(\mathrm{Ar})_{3} \mathrm{CorCo}^{\mathrm{III}}(\mathrm{CN})(\mathrm{Py})\right]^{-} \rightleftharpoons(\mathrm{Ar})_{3} \mathrm{Cor}^{\bullet} \mathrm{Co}^{\mathrm{III}}(\mathrm{CN})(\mathrm{Py})+\mathrm{e}^{-}}
\end{aligned}
$$

$$
\left[(\mathrm{Ar})_{3} \mathrm{CorCo}^{\mathrm{III}}(\mathrm{CN})_{2}\right]^{2-} \rightleftharpoons\left[(\mathrm{Ar})_{3} \mathrm{Cor} \cdot \mathrm{Co}^{\mathrm{III}}(\mathrm{CN})_{2}\right]^{-}+\mathrm{e}^{-}
$$

The measured half-wave potentials for oxidation of the three corroles in Figure 9 vary directly with charge on the electroactive species, these values being 0 for $\mathbf{1}(\mathbf{P y})_{2},-1$ for $\mathbf{1}(\mathbf{C N})(\mathbf{P y})$, and -2 in the case of $\mathbf{1}(\mathbf{C N})_{2}$, and a plot of $E_{1 / 2}$ versus charge is linear with a slope of $340 \mathrm{mV} /$ charge, a correlation coefficient of $R^{2}=0.996$ with a standard error (or deviation) of the slope $\left(S_{\mathrm{b}}\right)$ of $20 \mathrm{mV} /$ charge (see Figure 10). Linear plots between $E_{1 / 2}$ and charge on the electroactive corrole are also seen for the different ligated forms of compounds 2 and 3, where slopes range from 330 to 340 $\mathrm{mV} /$ charge. Again, high correlation coefficients and low uncertainty of the slopes (i.e., small $S_{\mathrm{b}}$ values) are observed as seen in the figure.

The reversible oxidations of the bis-ligated corroles 1-3 in pyridine are consistent with a rapid ring-centered electron transfer and no change in axial coordination between the initial and singly oxidized forms of the corrole. This is not the case for the first reduction, however, where a rapid loss of both axial ligands occurs after electron addition as also described in Scheme 2 when the reactions were performed in DMSO. The average difference between the first cathodic reduction peak and the coupled anodic reoxidation peak $\left(\Delta E_{\mathrm{p}}\right)$ varies from $0.40 \mathrm{~V}$ for $\mathbf{1}(\mathbf{P y})_{2}-3(\mathbf{P y})_{2}$ to $\sim 1.0 \mathrm{~V}$ in the case of the mixedligand or bis- $\mathrm{CN}$ derivatives. These values are given in Table 5, and examples of cyclic voltammograms illustrating the initial reduction and reoxidation of $\mathbf{1}(\mathrm{Py})_{2}, \mathbf{1}(\mathrm{CN})(\mathrm{Py})$, and $\mathbf{1}(\mathrm{CN})_{2}$, are shown in Figure 11.

The same four-coordinate $\left[(\mathrm{Ar})_{3} \mathrm{CorCo}^{\mathrm{II}}\right]^{-}$product is formed after the first reduction of each corrole in Figure 11 as evidenced by the virtually identical reoxidation peak potential of $-0.48 /-0.50 \mathrm{~V}$ on the return potential sweep. This irreversible reoxidation of $\left[(\mathrm{Ar})_{3} \mathrm{CorCo}^{\mathrm{II}}\right]^{-}$to $(\mathrm{Ar})_{3} \mathrm{Cor}-$ $\mathrm{Co}^{\mathrm{III}}(\mathrm{Py})_{2}$ follows an electrochemical EC mechanism described by eqs $14 \mathrm{a}$ and $14 \mathrm{~b}$.

$$
\begin{aligned}
& {\left[(\mathrm{Ar})_{3} \mathrm{CorCo}^{\mathrm{II}}\right]^{-} \rightleftharpoons(\mathrm{Ar})_{3} \mathrm{Cor}^{\bullet} \mathrm{Co}^{\mathrm{II}}+\mathrm{e}^{-}} \\
& (\mathrm{Ar})_{3} \mathrm{Cor}^{\bullet} \mathrm{Co}^{\mathrm{II}}+2 \mathrm{Py} \rightarrow(\mathrm{Ar})_{3} \mathrm{CorCo}^{\mathrm{III}}(\mathrm{Py})_{2}
\end{aligned}
$$

A further reversible oxidation of $(\mathrm{Ar})_{3} \mathrm{CorCo}^{\mathrm{III}}(\mathrm{Py})_{2}$ to $\left[(\mathrm{Ar})_{3} \operatorname{CorCo}^{\mathrm{III}}(\mathrm{Py})_{2}\right]^{+}$is also seen at $E_{1 / 2}=0.47 \mathrm{~V}$ for $\mathbf{1}(\mathbf{P y})_{2}$ and $\mathbf{1}(\mathbf{C N})(\mathrm{Py})$ on the reverse potential scan of Figure $11 \mathrm{a}, \mathrm{b}$. This process is located at $E_{1 / 2}=0.47 \mathrm{~V}$ when directly oxidizing $\mathbf{1}(\mathbf{P y})_{2}$ but not observed when directly oxidizing $\mathbf{1}(\mathbf{C N})(\mathbf{P y})$ (see Figure 9) thus confirming the formation of the bis-Py adduct as shown in eqs $14 \mathrm{a}$ and $14 \mathrm{~b}$. The presence of a reoxidation peak at $-0.48 \mathrm{~V}$ after reduction of $\mathbf{1}(\mathrm{CN})_{2}$ should also lead to an oxidation at $0.47 \mathrm{~V}$ in pyridine containing TBACN (Figure 11c), but the potential window in this solvent is limited due to the oxidation of free $\mathrm{CN}^{-}$, thus preventing the process from being observed.

Spectroscopic and Electrochemical Linear Free Energy Relationships. The series of corroles characterized in this study offer a unique opportunity to probe substituent effects through well-known electrochemical and spectroscopic linear free energy relationships (LFER) involving tetrapyrroles ${ }^{4,18,19,42,46,47,56,75,80,83-86}$ and to also explore how the data might relate to established criteria for determining noninnocence in corrole systems. ${ }^{57}$

UV-visible spectroscopic criteria employed by Ghosh and co-workers. $^{4,37,38,44,52,53,87,88}$ in multiple reports have shown the ability of electron-donating or -withdrawing groups on the 
Table 4. UV-Visible Spectral Data of Singly Electrooxidized Corroles in DMSO, 0.1 M TBAP

\begin{tabular}{|c|c|c|c|c|c|}
\hline \multirow[b]{3}{*}{ solvent } & \multirow[b]{3}{*}{ cpd } & \multicolumn{4}{|c|}{$\lambda, \mathrm{nm}\left(\varepsilon \cdot 10^{-4} \mathrm{M}^{-1} \cdot \mathrm{cm}^{-1}\right)$} \\
\hline & & & & & \\
\hline & & \multicolumn{2}{|c|}{ Soret region } & Q band & NIR \\
\hline \multirow[t]{9}{*}{ DMSO } & 1(DMSO) & $436(4.3)$ & & & $706(0.7)$ \\
\hline & 2 (DMSO) & $430(4.0)$ & & & $703(0.6)$ \\
\hline & 3(DMSO) & $423(4.1)$ & $468(2.2)$ & & $715(0.5)$ \\
\hline & $1(\mathrm{CN})$ & $432(5.4)$ & & & $721(0.6)$ \\
\hline & $2(\mathrm{CN})$ & $427(3.8)$ & & & $719(0.5)$ \\
\hline & $3(\mathrm{CN})$ & $412(2.9)$ & $464(2.3)$ & & $739(0.5)$ \\
\hline & $1(\mathrm{CN})_{2}$ & $430(5.0)$ & & & $748(0.8)$ \\
\hline & $2(\mathrm{CN})_{2}$ & $435(3.3)$ & & & $745(0.6)$ \\
\hline & $3(\mathrm{CN})_{2}$ & $462(3.2)$ & & $531(1.3)$ & $760(0.6)$ \\
\hline
\end{tabular}

Scheme 2. Electron Transfer Mechanism for the Mono-DMSO, Mono-CN, and Bis-CN adducts in DMSO Containing 0.1 M TBAP $^{a}$

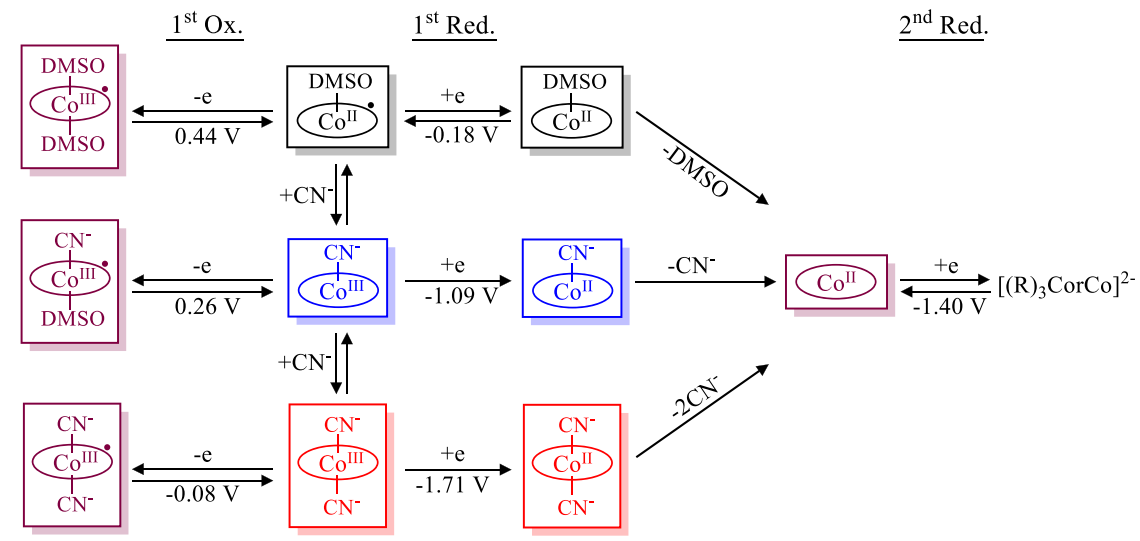

${ }^{a_{T}}$ The potentials are given for $\mathbf{1}(\mathrm{DMSO}), \mathbf{1}(\mathrm{CN})$, and $\mathbf{1}(\mathrm{CN})_{2}$.

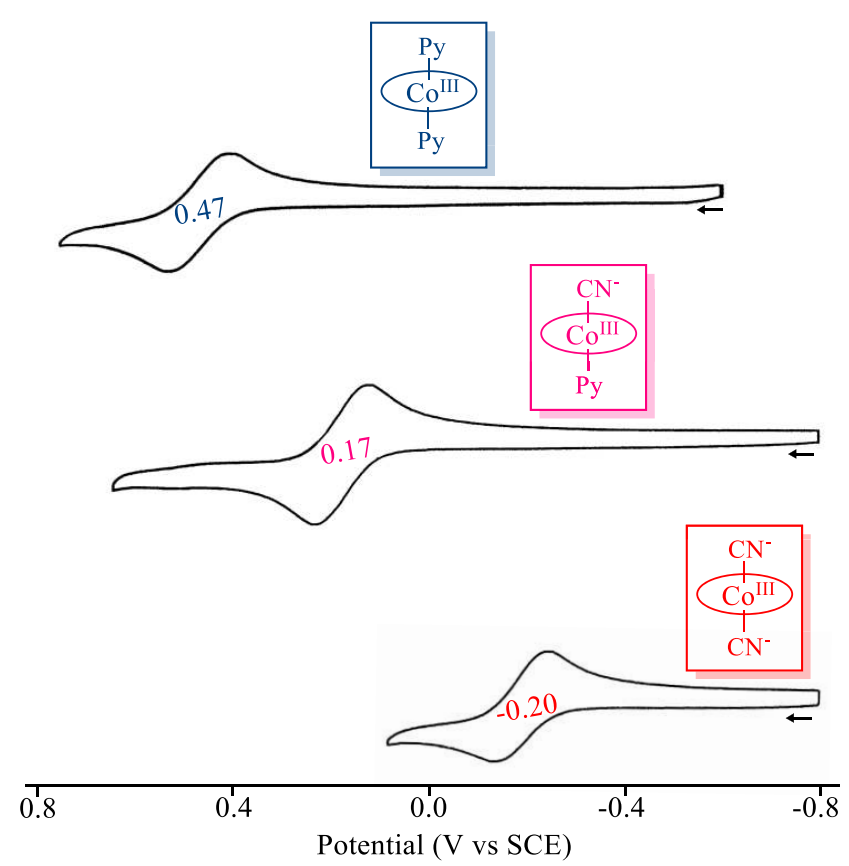

Figure 9. Cyclic voltammograms illustrating the oxidation of $\mathbf{1}(\mathrm{Py})_{2}$, $\mathbf{1}(\mathrm{CN})(\mathrm{Py})$, and $\mathbf{1}(\mathrm{CN})_{2}$ in pyridine containing $0.1 \mathrm{M}$ TBAP. Scan rate $=0.1 \mathrm{~V} / \mathrm{s}$. meso-phenyl rings of a triarylcorroles to induce, or not induce, significant shifts in the Soret band depending on the noninnocence, or innocence, of the macrocyclic ligand. Noninnocent metallocorrole systems display a monotonic red-shift of the Soret band with increasing electron-donating properties of the meso-phenyl substituent due to intense arylto-corrole charge transfer transitions, while little to no variation of the Soret band energy is observed for innocent corrole macrocycles, despite changes in the peripheral substituents. This behavior can be visualized by plots of the Soret band energy (in $\mathrm{cm}^{-1}$ ) versus the Hammett substituent constant of the meso-phenyl ring. Such a plot is given in Figure 12 for $\mathbf{1}(\mathrm{CN})-\mathbf{3}(\mathrm{CN})$ and $\mathbf{1}(\mathbf{C N})_{2}-\mathbf{3}(\mathbf{C N})_{2}$ in DMSO, where the Hammett substituent constants $(3 \sigma)$ are given in Table 2 and were taken from the literature. ${ }^{76}$ As seen in the figure, a linear hypsochromic (blue) shift is observed upon going from the $p$ $\mathrm{CNPh}$ derivatives (compound 1 ) to the corroles containing electron-donating $p$-OMePh substituents, $3(\mathrm{CN})$ to $3(\mathrm{CN})_{2}$. A similar blue-shift of the Soret band as a function of the Hammett substituent constant was previously reported ${ }^{88}$ for a series of $\sigma$-bonded $\mathrm{Mn}^{\mathrm{IV}}$ triarylcorroles, where the ligand was assigned as innocent (i.e., a trivalent corrole macrocycle), and thus the observed wavelength shift as a function of $3 \sigma$ should rule out a noninnocent macrocyclic ligand for both the monoand bis- $\mathrm{CN}$ adducts in the current study.

The wavelengths in Figure 12 correspond to the highestenergy (most blue-shifted) Soret band for the bis-CN adducts, but all three of the "split Soret" bands of the bis-CN complexes 
Table 5. Half-wave or Peak Potentials $\left(E_{1 / 2}\right.$ or $E_{\mathrm{p}}, \mathrm{V}$ vs SCE) of the Investigated Compounds in Pyridine Containing $0.1 \mathrm{M}$ TBAP with and without Added TBACN ${ }^{a}$

\begin{tabular}{|c|c|c|c|c|c|c|}
\hline \multirow[b]{4}{*}{ solution condition } & \multirow[b]{4}{*}{ cpd } & \multicolumn{5}{|c|}{ potential (V vs SCE) } \\
\hline & & \multicolumn{2}{|c|}{ oxidation } & \multicolumn{3}{|c|}{ reduction } \\
\hline & & \multirow{2}{*}{$\begin{array}{l}\text { 2nd } \\
E_{1 / 2}\end{array}$} & \multirow{2}{*}{$\begin{array}{c}\text { 1st } \\
E_{1 / 2}\end{array}$} & \multicolumn{2}{|c|}{ 1st } & \multirow{2}{*}{$\begin{array}{l}\text { 2nd } \\
E_{1 / 2}\end{array}$} \\
\hline & & & & $E_{\mathrm{pc}}\left(E_{\mathrm{pa}}\right)$ & $\Delta E_{\mathrm{p}}^{b}$ & \\
\hline \multirow[t]{6}{*}{ pyridine } & $1(\mathrm{Py})_{2}$ & & 0.47 & $-1.01(-0.48)$ & 0.53 & -1.48 \\
\hline & $2(\mathrm{Py})_{2}$ & & 0.44 & $-0.91(-0.51)$ & 0.40 & -1.52 \\
\hline & $3(\mathrm{Py})_{2}$ & $0.85^{c}$ & 0.23 & $-0.87(-0.58)$ & 0.29 & -1.63 \\
\hline & $1(\mathrm{CN})(\mathrm{Py})$ & & 0.17 & $-1.46(-0.50)$ & 0.96 & $-1.56^{c}$ \\
\hline & $2(\mathrm{CN})(\mathrm{Py})$ & & 0.13 & $-1.49(-0.52)$ & 0.97 & $-1.56^{c}$ \\
\hline & $3(\mathrm{CN})(\mathrm{Py})$ & 0.56 & -0.07 & $-1.47(-0.58)$ & 0.89 & -1.63 \\
\hline \multirow[t]{3}{*}{ pyridine + TBACN } & $1(\mathrm{CN})_{2}$ & & -0.20 & $-1.55(-0.48)$ & 1.07 & $-1.55^{d}$ \\
\hline & $2(\mathrm{CN})_{2}$ & & -0.23 & $-1.54(-0.51)$ & 1.03 & $-1.54^{d}$ \\
\hline & $3(\mathrm{CN})_{2}$ & & -0.43 & $-1.67(-0.59)$ & 1.08 & $-1.67^{d}$ \\
\hline
\end{tabular}

${ }^{a}$ All measurements were made at a scan rate of $0.1 \mathrm{~V} / \mathrm{s} .{ }^{b} \Delta E_{\mathrm{p}}=E_{\mathrm{pa}}-E_{\mathrm{pc}}$ for 1st reduction. ${ }^{c}$ Irreversible peak potential. ${ }^{d}$ Overlapping and irreversible two electron process.

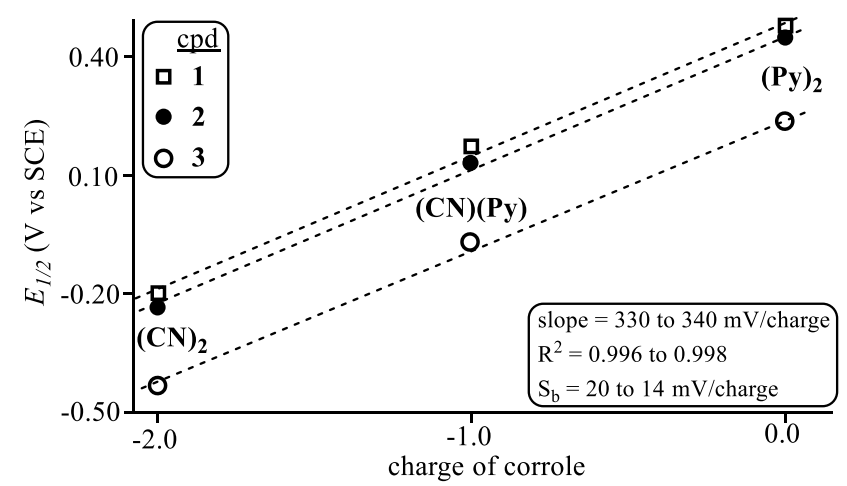

Figure 10. Plot of $E_{1 / 2}$ for the first oxidation process of the bis-Py, mixed ligand $(\mathrm{CN})(\mathrm{Py})$, and bis-CN adducts vs charge of corrole complexes in pyridine. Correlation coefficients $\left(R^{2}\right)$ and standard errors (or deviations) of the slopes $\left(S_{\mathrm{b}}\right)$ are given in the figure.

(Table 1) give the same monotonic blue-shift when plotted against the sum of the Hammett substituent constants $(3 \sigma)$. This behavior is opposite to the previously assigned noninnocent mono-DMSO complexes, where a clear red-shift of the Soret band is observed upon going from 1(DMSO) $(393 \mathrm{~nm})$ to 3 (DMSO) $(405 \mathrm{~nm})$ in a DMSO solvent (see Table 1).

Implementing the same spectroscopic criteria for the singly oxidized bis-CN corroles reveals a drastically different behavior as shown in Figure 13. In this case, a plot of the most-intense Soret band energy in the singly oxidized spectra of $1(\mathrm{CN})_{2}-$ $3(\mathrm{CN})_{2}$ in DMSO (Figure S17) shows a nicely correlated redshift in the Soret band position with increasing electrondonating property of the meso-phenyl substituent (Figure 13b). This behavior contrasts with what is observed for the same compounds before oxidation (Figure 13a) and suggests that the singly oxidized corroles, formulated in eq 11 as $\left[(\mathrm{Ar})_{3} \mathrm{Cor}^{\bullet} \mathrm{Co}{ }^{\mathrm{III}}(\mathrm{CN})_{2}\right]^{-}$, contain noninnocent macrocycles, where an equilibrium exists between a $\mathrm{Co}$ (III) $\pi$-cation radical and a formal $\mathrm{Co}(\mathrm{IV})$ as shown in eq 15.

$$
\left[(\mathrm{Ar})_{3} \mathrm{Cor}^{\bullet} \mathrm{Co}^{\mathrm{III}}(\mathrm{CN})_{2}\right]^{-} \rightleftharpoons\left[(\mathrm{Ar})_{3} \mathrm{CorCo}^{\mathrm{IV}}(\mathrm{CN})_{2}\right]^{-}
$$

The postulate of a $\mathrm{Co}(\mathrm{IV})$ oxidation product is consistent with reports in the literature, which suggests some cobalt(IV) character of singly oxidized cobalt triarylcorroles containing anionic axial ligands. 15,73

Electrochemical free energy relationships between the first oxidation potential and the Hammett substituent constant on the meso-phenyl ring were also examined in three solvents, and diagnostic $E_{1 / 2}$ versus $3 \sigma$ plots are given in Figure 14a (DMSO), Figure $14 \mathrm{~b}$ (pyridine), and Figure S23 $\left(\mathrm{CH}_{2} \mathrm{Cl}_{2}\right)$, where axial ligation of the reacting species is indicated in the figures, and a summary of the plots including correlation coefficients $\left(R^{2}\right)$ is given in Table 6 .

Although there are only three points in each plot of Figure 14 , a good correlation is observed (see Table 6) for the linear free energy relationship, which is described by eq 16, where $\rho$, the reaction constant, is the slope of the line. ${ }^{76,89}$

$$
\Delta E_{1 / 2}=3 \sigma \rho
$$

A quite similar slope ( $\rho$ value) of $83-90 \mathrm{mV}$ is observed for oxidation of each bis-ligated corrole in the current study independent of solvent, while a much smaller substituent effect (i.e., smaller $\rho$ value) is seen for the two series of fivecoordinate compounds in DMSO, where $\rho=42-47 \mathrm{mV}$ (Figure 14a), or $\mathrm{CH}_{2} \mathrm{Cl}_{2}$, where $\rho=54-55 \mathrm{mV}$ (Figure S22 and Table 6 ). The increased $\rho$ value upon going from a highdielectric solvent such as DMSO $(\varepsilon=46)$ to a relatively lowdielectric solvent such as $\mathrm{CH}_{2} \mathrm{Cl}_{2}(\varepsilon=9)$ is consistent with factors known to affect the electrochemical reaction constant. ${ }^{84}$

The decrease in substituent effect observed upon lowering the coordination number from six- to five-coordinate is consistent with a reduced interaction between the meso-phenyl substituents and the site of electrooxidation. This could indicate a different location of electron abstraction in the pentacoordinate and hexacoordinate species, or it could be due to a change in the cobalt out-of-plane distance upon oxidation. As schematically depicted in Scheme 3, larger changes of the cobalt-corrole planarity would be expected in five-coordinate complexes upon oxidation, as they convert to the more planar six-coordinate arrangement, whereas electrooxidation of the six-coordinate derivatives could experience minimal changes in the cobalt out-of-plane distance upon electron abstraction, thus resulting in an enhanced substituent effect, that is, an increased $\rho$ value. Similar conformational effects on electronic nature and/or reaction constants $(\rho)$ have been reported in the literature for other tetrapyrroles, ${ }^{84,86,90-95}$ and specifically 

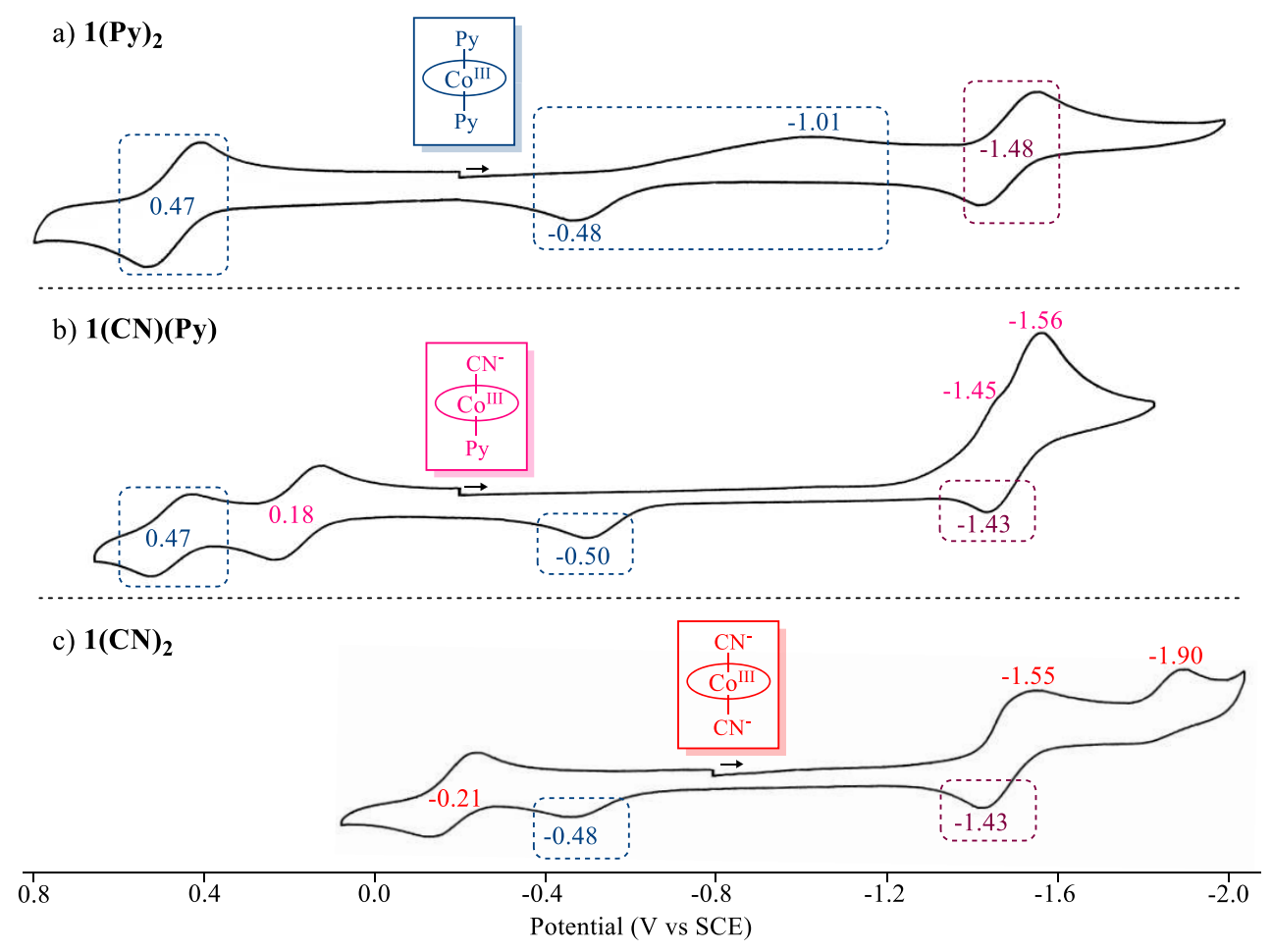

Figure 11. Cyclic voltammograms of $(\mathrm{a}) \mathbf{1}(\mathrm{Py})_{2},(\mathrm{~b}) \mathbf{1}(\mathrm{CN})(\mathrm{Py})$, and $(\mathrm{c}) \mathbf{1}(\mathrm{CN})_{2}$ in pyridine containing $0.1 \mathrm{M}$ TBAP. The scan was initiated in a negative direction starting from -0.20 or $-0.80 \mathrm{~V}$ as indicated. The bis- $\mathrm{CN}$ adduct was generated in solutions containing excess TBACN. Scan rate $=0.1 \mathrm{~V} / \mathrm{s}$.

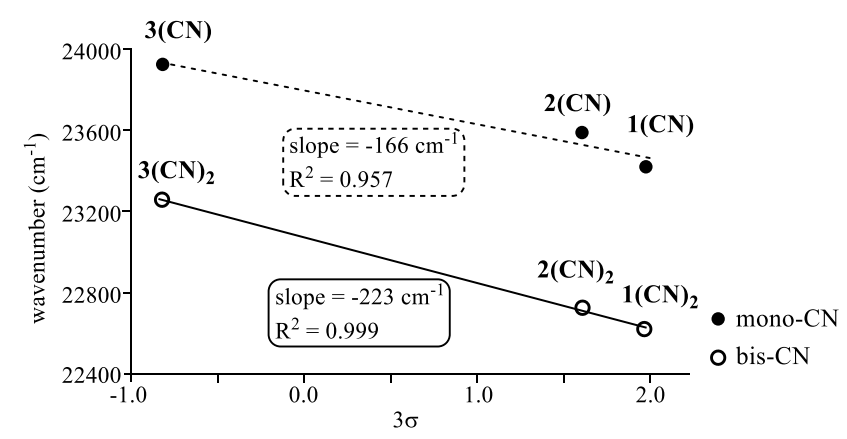

Figure 12. Plot of wavenumber $\left(\mathrm{cm}^{-1}\right)$ for the highest-energy Soret band of the mono- $\mathrm{CN}(\bullet)$ and bis-CN adducts $(\mathrm{O})$ vs $3 \sigma$ in DMSO.

noted $\rho$-value of $77 \mathrm{mV}$ for the first oxidation of $[\mathrm{T}(p-\mathrm{X}-\mathrm{P}) \mathrm{P}]$ $\mathrm{Ni}$ as compared to a minimized $\rho$-value of $27-28 \mathrm{mV}$ for the same process of highly distorted $\left[\mathrm{Br}_{8} \mathrm{~T}(p-\mathrm{X}-\mathrm{P}) \mathrm{P}\right] \mathrm{Ni}$ and $\left[\mathrm{Cl}_{8} \mathrm{~T}(p-\mathrm{P}-\mathrm{X}) \mathrm{P}\right] \mathrm{Ni}$ derivatives. $^{92}$ Moreover, nearly identical $\rho$-values between 57 and $60 \mathrm{mV}$ for the first oxidation in several series of mono- $\mathrm{PPh}_{3}$ meso-substituted cobalt corroles have been reported in both $\mathrm{CH}_{2} \mathrm{Cl}_{2}{ }^{18,56}$ and $\mathrm{PhCN}^{75}$ and are analogous to the reaction constants obtained for the monoDMSO and mono-CN derivatives. Further confirmation of the postulated conformational effects comes from a study that compared $\rho$ values for the oxidation of $\beta$-brominated and $\beta$ unbrominated copper meso-triarylcorroles, which remain fourcoordinate before and after oxidation. The slope of the electrochemical linear free energy relationship was found to be $95 \mathrm{mV}$ for the planar nonbrominated copper corrole, which can be compared to the planar six-coordinate cobalt corroles in this study, while the $\rho$-value of $58 \mathrm{mV}$ was reported for
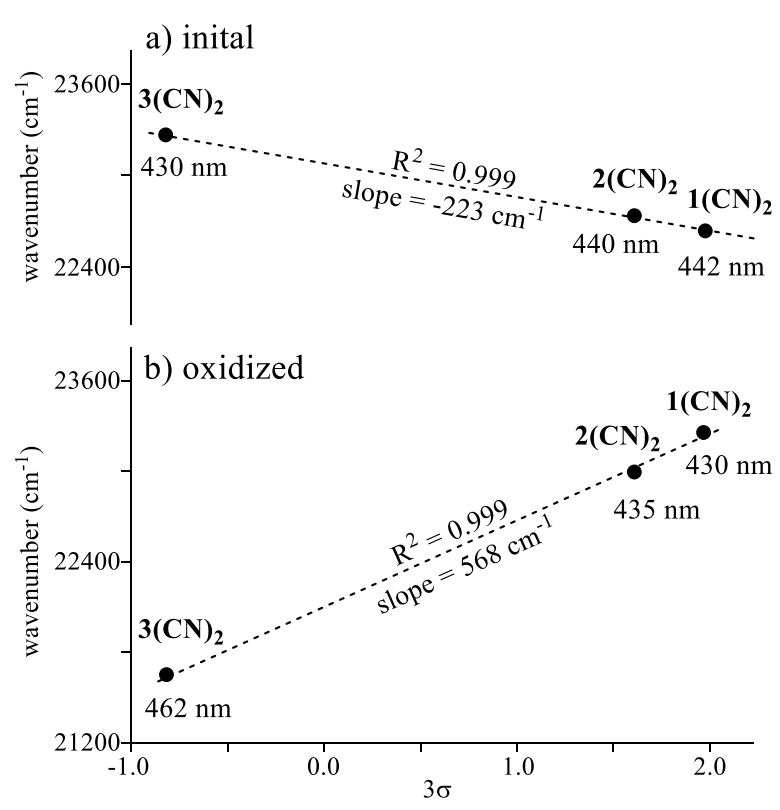

Figure 13. Plot of wavenumber $\left(\mathrm{cm}^{-1}\right)$ for (a) the most blue-shifted Soret band of the bis-CN adduct in DMSO vs $3 \sigma$ and (b) the Soret band of the singly oxidized bis-CN adduct in DMSO.

compounds in the structurally distorted octabrominated copper corrole series. ${ }^{4}$

In addition to the LFER described above, the spectroscopically determined and theoretical $\log K_{2}$ values for the binding of a second cyanide ligand to $\mathbf{1}(\mathbf{C N})-\mathbf{3}(\mathbf{C N})$ (see Table 2) also correlate $\left(R^{2}=0.995\right)$ with the Hammett substituent constants $(3 \sigma)$ as shown by the plot in Figure 15. 


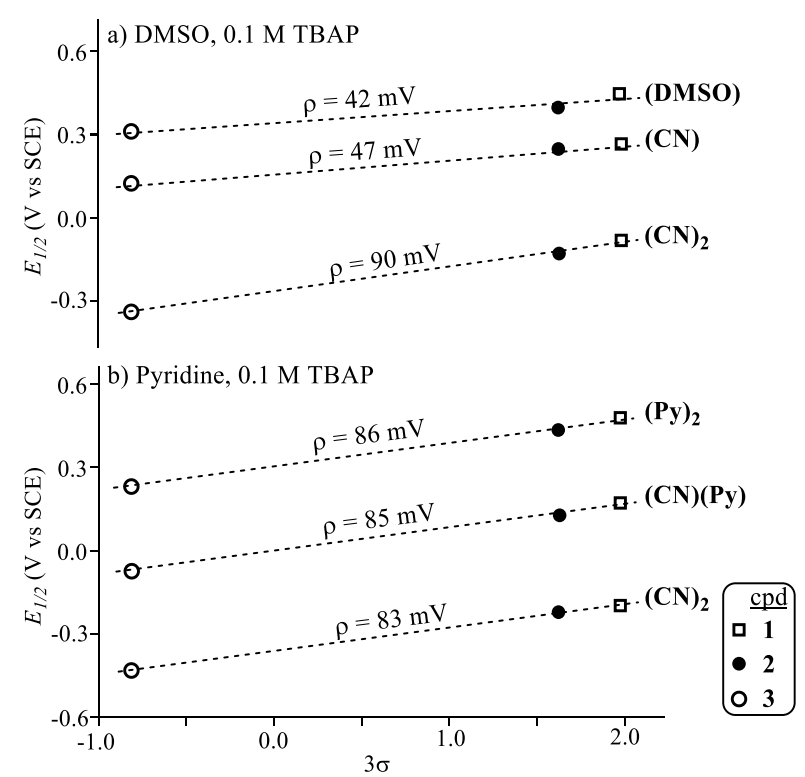

Figure 14. Plot of $E_{1 / 2}$ vs $3 \sigma$ for the first oxidation process corresponding to (a) the mono-DMSO, mono- $\mathrm{CN}$, and bis-CN adducts of 1-3 in DMSO containing 0.1 M TBAP and (b) the bis-Py, mixed ligand $(\mathrm{CN})(\mathrm{Py})$, and bis- $\mathrm{CN}$ adducts of $1-3$ in pyridine containing $0.1 \mathrm{M}$ TBAP. The bis-CN adduct in each case was generated in solutions containing excess TBACN.

Table 6. $\rho$ Values (in $\mathrm{mV}$ ) for the First Oxidation of Each Ligated Form of the Cobalt Corroles 1-3 along with the $R^{2}$ Values for the Linear Least-Squares Fit and the Standard Errors (or Deviations) of the Slopes $\left(S_{\mathrm{b}}\right)$

$\begin{array}{clccc}\text { solvent } & \text { axial ligation } & \rho(\mathrm{mV}) & R^{2} & S_{\mathrm{b}}(\mathrm{mV}) \\ \text { DMSO } & (\mathrm{DMSO}) & 42 & 0.928 & 11.7 \\ & (\mathrm{CN}) & 47 & 0.974 & 7.7 \\ & (\mathrm{CN})_{2} & 90 & 0.996 & 5.8 \\ \text { pyridine } & (\mathrm{Py})_{2} & 86 & 1.000 & 0.3 \\ & (\mathrm{CN})(\mathrm{Py}) & 85 & 0.999 & 3.2 \\ & (\mathrm{CN})_{2} & 83 & 1.000 & 0.1 \\ \mathrm{CH}_{2} \mathrm{Cl}_{2} & (\mathrm{DMSO}) & 54 & 1.000 & 0.2 \\ & (\mathrm{CN}) & 55 & 0.945 & 13.3 \\ & (\mathrm{CN})_{2} & 89 & 0.989 & 9.3\end{array}$

Scheme 3. Schematic Representation of Possible Changes upon Going from the (a) Five-Coordinate Mono-DMSO or Mono-CN Cobalt Corrole to (b) a Six-Coordinate Complex

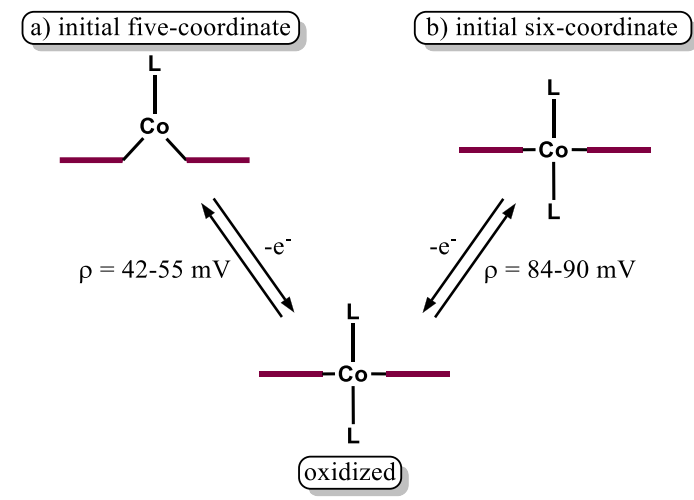

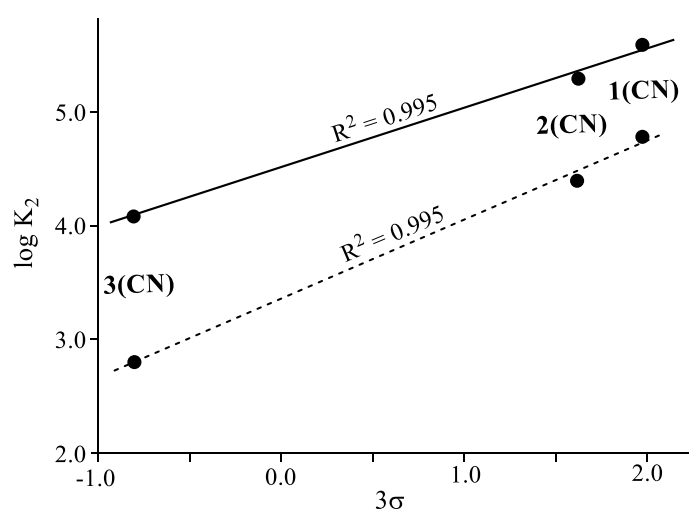

Figure 15. Plot of the spectroscopically determined ( $\cdots)$ and computed $(-) \log K_{2}$ vs $3 \sigma$ for $\mathbf{1}(\mathbf{C N})-\mathbf{3}(\mathbf{C N})$ in DMSO (see Table 2 and Figures 3 and S8).

\section{CONCLUSIONS}

Self-consistent proof of the aforementioned change from a noninnocent ligand in the case of the mono-DMSO complexes to an innocent corrole macrocycle in the mono- $\mathrm{CN}$ and bis$\mathrm{CN}$ adducts was validated through electrochemical and spectroscopic criteria. Further LFER were established between experimental and theoretically calculated binding constants for addition of the second cyanide ligand $\left(\log K_{2}\right)$ to the mono$\mathrm{CN}$ derivatives, $\mathbf{1}(\mathbf{C N})-\mathbf{3}(\mathbf{C N})$. Electrochemical LFER between half-wave potentials, revealing plausible structural conformations for the electroactive five- and six-coordinate cobalt corrole complexes, were established, and linear relationships between oxidation potentials and key spectroscopic features were shown to vary as a function of the charge on the corrole complex. Overall, the data for these corrole complexes and linear relationships described above should help elucidate future predictable trends in the physicochemical properties of yet-to-be studied corrole systems.

\section{ASSOCIATED CONTENT}

\section{Supporting Information}

The Supporting Information is available free of charge at https://pubs.acs.org/doi/10.1021/acs.inorgchem.0c01037.

${ }^{1} \mathrm{H}$ NMR of corroles $\mathbf{1}(\mathrm{CN})$ and $2(\mathrm{CN})$. LRMS and HRMS (ESI) spectra of corroles $\mathbf{1}(\mathrm{CN})-\mathbf{3}(\mathrm{CN})$. UV data in $\mathrm{CH}_{2} \mathrm{Cl}_{2}, \mathrm{UV}$-visible spectra of $\mathbf{1}(\mathbf{P y})_{2}-\mathbf{3}(\mathbf{P y})_{2}$ and $\mathbf{1}(\mathrm{CN})(\mathrm{Py})-\mathbf{3}(\mathrm{CN})(\mathrm{Py})$, time-dependent conversion of $\mathbf{1}(\mathrm{CN})(\mathrm{Py})$ to $\mathbf{1}(\mathrm{Py})_{2}$ in pyridine and plot of $\mathrm{Q}$ band ratio of bis-CN adducts in pyridine versus charge. TBACN titration of $3(\mathbf{C N})$ and voltammograms of 2(DMSO), $2(\mathrm{CN})$, and $2(\mathrm{CN})_{2}$ in DMSO. Cyclic voltammograms of 1(DMSO)-3(DMSO), 1(CN)$3(\mathrm{CN})$, and $1(\mathrm{CN})_{2}-3(\mathrm{CN})_{2}$ and plot of $E_{1 / 2}$ versus $3 \sigma$ for the first oxidation process in $\mathrm{CH}_{2} \mathrm{Cl}_{2}$. Spectral changes associated with the oxidative conversion monoDMSO, mono-CN, and bis- $\mathrm{CN}$ adducts and plot of wavenumber $\left(\mathrm{cm}^{-1}\right)$ for the NIR band of the singly oxidized corrole versus charge in DMSO. Cyclic voltammograms of $\mathbf{2}(\mathbf{P y})_{2}-\mathbf{3}(\mathbf{P y})_{2}, \quad \mathbf{2}(\mathrm{CN})(\mathbf{P y})-$ $3(\mathrm{CN})(\mathrm{Py})$, and $2(\mathrm{CN})_{2}-3(\mathrm{CN})_{2}$ in pyridine and in $\mathrm{CH}_{2} \mathrm{Cl}_{2}$ corresponding to $1-3$. Spin density for 1(DMSO), 2(DMSO), and 3(DMSO) at the B3LYPD3/def2-SVP level for the broken symmetry state, and computational details (PDF) 


\section{AUTHOR INFORMATION}

\section{Corresponding Authors}

Roberto Paolesse - Department of Chemical Science and Technology, University of Rome Tor Vergata, Rome 00133, Italy; @ orcid.org/0000-0002-2380-1404; Phone: +3906 72 5947 52; Email: roberto.paolesse@uniroma2.it

Claude P. Gros - Université Bourgogne Franche-Comte, ICMUB (UMR CNRS 6302), Dijon, Cedex 21078, France; (1) orcid.org/0000-0002-6966-947X; Phone: +33 (0)3 8039 61 12; Email: claude.gros@u-bourgogne.fr

Karl M. Kadish - Department of Chemistry, University of Houston, Houston 77204-5003, Texas, United States; (1) orcid.org/0000-0003-4586-6732; Phone: (+1) 713-7432740; Email: kkadish@uh.edu

\section{Authors}

W. Ryan Osterloh - Department of Chemistry, University of Houston, Houston 77204-5003, Texas, United States; (ㄱ) orcid.org/0000-0001-9127-2519

Nicolas Desbois - Université Bourgogne Franche-Comté, ICMUB (UMR CNRS 6302), Dijon, Cedex 21078, France

Valentin Quesneau - Université Bourgogne Franche-Comté, ICMUB (UMR CNRS 6302), Dijon, Cedex 21078, France

Stéphane Brandès - Université Bourgogne Franche-Comté, ICMUB (UMR CNRS 6302), Dijon, Cedex 21078, France; (1) orcid.org/0000-0001-6923-1630

Paul Fleurat-Lessard - Université Bourgogne Franche-Comte, ICMUB (UMR CNRS 6302), Dijon, Cedex 21078, France; ○ orcid.org/0000-0003-3114-2522

Yuanyuan Fang - Department of Chemistry, University of Houston, Houston 77204-5003, Texas, United States; (ㄷ) orcid.org/0000-0002-4562-0727

Virginie Blondeau-Patissier - Department Time-Frequency, Université Bourgogne Franche-Comté, Institut FEMTO-ST (UMR CNRS 6174), Besançon Cedex 25030, France

Complete contact information is available at:

https://pubs.acs.org/10.1021/acs.inorgchem.0c01037

\section{Notes}

The authors declare no competing financial interest.

\section{ACKNOWLEDGMENTS}

This work was supported by the Robert A. Welch Foundation (K.M.K., Grant No. E-680), the CNRS (UMR UB-CNRS 6302), the "Universite Bourgogne Franche-Comté", and the "Conseil Régional de Bourgogne" through the Plan d'Actions Régional pour l'Innovation (PARI II CDEA) and the European Union through the PO FEDER-FSE Bourgogne 2014/2020 (via the CoMICS program, Chemistry of Molecular Interactions: Catalysis \& Sensors and the ISITE $\mathrm{CO}_{2}$ DECIN). V.Q. warmly thanks $\mathrm{CRB}$ for a $\mathrm{PhD}$ grant (JCE program). The French Research Agency (ANR) is also acknowledged for financial support (AAPG 2015, ANR-15-CE04-0008, $\mathrm{CO}^{3}$ SENS project). The authors wish also to warmly thank S. Pacquelet for technical assistance and the "Plateforme d'Analyse Chimique et de Synthèse Moléculaire de l'Université de Bourgogne" (SATT SAYENS, PACSMUB, http://www. $w p c m . f r)$ for access to spectroscopy instrumentation (NMR, IR, ESI, LRMS, and HR-MS). Calculations were performed using HPC resources from DNUM CCUB (Centre de Calcul de l’Université de Bourgogne).

\section{REFERENCES}

(1) Aviv-Harel, I.; Gross, Z. Coordination Chemistry of Corroles with Focus on Main Group Elements. Coord. Chem. Rev. 2011, 255, $717-736$.

(2) Fang, Y.; Ou, Z.; Kadish, K. M. Electrochemistry of Corroles in Nonaqueous Media. Chem. Rev. 2017, 117, 3377-3419.

(3) Ghosh, A. Electronic Structure of Corrole Derivatives: Insights from Molecular Structures, Spectroscopy, Electrochemistry, and Quantum Chemical Calculations. Chem. Rev. 2017, 117, 3798-3881.

(4) Ghosh, A.; Steene, E. High-valent Transition Metal Centers versus Noninnocent Ligands in Metallocorroles: Insights from Electrochemistry and Implications for High-valent Heme Protein Intermediates. J. Inorg. Biochem. 2002, 91, 423-436.

(5) Erben, C.; Will, S.; Kadish, K. M. Metallocorroles: Molecular Structure, Spectroscopy and Electronic States. In The Porphyrin Handbook, Vol. 2; Kadish, K. M.; Smith, K. M.; Guilard, R., Eds.; Academic Press: Burlington, MA, 2000; pp 233-300.

(6) Guilard, R.; Barbe, J.-M.; Stern, C.; Kadish, K. M. New Developments in Corrole Chemistry: Special Emphasis on Face-toFace Bismacrocycles. In The Porphyrin Handbook, Vol. 18; Kadish, K. M.; Smith, K. M.; Guilard, R., Eds.; Elsevier Science: San Diego, CA, 2003; pp 303-349.

(7) Gross, Z.; Gray, H. B. Oxidations Catalyzed by Metallocorroles. Adv. Synth. Catal. 2004, 346, 165-170.

(8) Ali, H.; van Lier, J. E. Porphyrins and Phthalocyanines as Photosensitizers and Radiosensitizers. In Handbook of Porphyrin Science, Vol. 4; Kadish, K. M.; Smith, K. M.; Guilard, R., Eds.; World Scientific: Singapore, 2010; pp 1-119.

(9) Fremond, L. Catalysis of the Electroreduction of Dioxygen by Cobalt(III) Corrole. Reactivity of Monocorrole, Biscorrole and Porphyrin-Corrole Dyads. Ph.D. Dissertation, University of Houston: Houston, TX, 2007.

(10) Mondal, B.; Sengupta, K.; Rana, A.; Mahammed, A.; Botoshansky, M.; Dey, S. G.; Gross, Z.; Dey, A. Cobalt Corrole Catalyst for Efficient Hydrogen Evolution Reaction from $\mathrm{H}_{2} \mathrm{O}$ under Ambient Conditions: Reactivity, Spectroscopy, and Density Functional Theory Calculations. Inorg. Chem. 2013, 52, 3381-3387.

(11) Mahammed, A.; Mondal, B.; Rana, A.; Dey, A.; Gross, Z. The Cobalt Corrole Catalyzed Hydrogen Evolution Reaction: Surprising Electronic Effects and Characterization of Key Reaction Intermediates. Chem. Commun. 2014, 50, 2725-2727.

(12) Mahammed, A.; Gross, Z. Metallocorroles as Electrocatalysts for the Oxygen Reduction Reaction (ORR). Isr. J. Chem. 2016, 56, $756-762$.

(13) Zhang, W.; Lai, W.; Cao, R. Energy-Related Small Molecule Activation Reactions: Oxygen Reduction and Hydrogen and Oxygen Evolution Reactions Catalyzed by Porphyrin- and Corrole-Based Systems. Chem. Rev. 2017, 117, 3717-3797.

(14) Friedman, A.; Landau, L.; Gonen, S.; Gross, Z.; Elbaz, L. Efficient Bio-Inspired Oxygen Reduction Electrocatalysis with Electropolymerized Cobalt Corroles. ACS Catal. 2018, 8, 5024-5031.

(15) Sinha, W.; Mizrahi, A.; Mahammed, A.; Tumanskii, B.; Gross, Z. Reactive Intermediates Involved in Cobalt Corrole Catalyzed Water Oxidation (and Oxygen Reduction). Inorg. Chem. 2018, 57, 478-485.

(16) Kadish, K. M.; Shen, J.; Frémond, L.; Chen, P.; El Ojaimi, M.; Chkounda, M.; Gros, C. P.; Barbe, J.-M.; Ohkubo, K.; Fukuzumi, S.; Guilard, R. Clarification of the Oxidation State of Cobalt Corroles in Heterogeneous and Homogeneous Catalytic Reduction of Dioxygen. Inorg. Chem. 2008, 47, 6726-6737.

(17) Kadish, K. M.; Frémond, L.; Ou, Z.; Shao, J.; Shi, C.; Anson, F. C.; Burdet, F.; Gros, C. P.; Barbe, J.-M.; Guilard, R. Cobalt(III) Corroles as Electrocatalysts for the Reduction of Dioxygen: Reactivity of a Monocorrole, Biscorroles, and Porphyrin-Corrole Dyads. J. Am. Chem. Soc. 2005, 127, 5625-5631.

(18) Li, B.; Ou, Z.; Meng, D.; Tang, J.; Fang, Y.; Liu, R.; Kadish, K. M. Cobalt Triarylcorroles Containing One, Two or Three Nitro Groups. Effect of $\mathrm{NO}_{2}$ Substitution on Electrochemical Properties 
and Catalytic Activity for Reduction of Molecular Oxygen in Acid Media. J. Inorg. Biochem. 2014, 136, 130-139.

(19) Ou, Z.; Lü, A.; Meng, D.; Huang, S.; Fang, Y.; Lu, G.; Kadish, K. M. Molecular Oxygen Reduction Electrocatalyzed by mesoSubstituted Cobalt Corroles Coated on Edge-Plane Pyrolytic Graphite Electrodes in Acidic Media. Inorg. Chem. 2012, 51, 88908896.

(20) Teo, R. D.; Hwang, J. Y.; Termini, J.; Gross, Z.; Gray, H. B. Fighting Cancer with Corroles. Chem. Rev. 2017, 117, 2711-2729.

(21) Lei, H.; Fang, H.; Han, Y.; Lai, W.; Fu, X.; Cao, R. Reactivity and Mechanism Studies of Hydrogen Evolution Catalyzed by Copper Corroles. ACS Catal. 2015, 5, 5145-5153.

(22) Wang, D.; Groves, J. T. Efficient Water Oxidation Catalyzed by Homogeneous Cationic Cobalt Porphyrins with Critical Roles for the Buffer Base. Proc. Natl. Acad. Sci. U. S. A. 2013, 110, 15579.

(23) Shpilman, J. S.; Friedman, A.; Zion, N.; Levy, N.; Major, D. T.; Elbaz, L. Combined Experimental and Theoretical Study of Cobalt Corroles as Catalysts for Oxygen Reduction Reaction. J. Phys. Chem. C 2019, 123, 30129-30136.

(24) Dogutan, D. K.; Stoian, S. A.; McGuire, R.; Schwalbe, M.; Teets, T. S.; Nocera, D. G. Hangman Corroles: Efficient Synthesis and Oxygen Reaction Chemistry. J. Am. Chem. Soc. 2011, 133, 131140.

(25) Lei, H.; Liu, C.; Wang, Z.; Zhang, Z.; Zhang, M.; Chang, X.; Zhang, W.; Cao, R. Noncovalent Immobilization of a PyreneModified Cobalt Corrole on Carbon Supports for Enhanced Electrocatalytic Oxygen Reduction and Oxygen Evolution in Aqueous Solutions. ACS Catal. 2016, 6, 6429-6437.

(26) Nardis, S.; Mandoj, F.; Stefanelli, M.; Paolesse, R. Metal Complexes of Corrole. Coord. Chem. Rev. 2019, 388, 360-405.

(27) Yadav, O.; Varshney, A.; Kumar, A.; Ratnesh, R. K.; Mehata, M. S. $\mathrm{A}_{2} \mathrm{~B}$ Corroles: Fluorescence Signaling Systems for Sensing Fluoride Ions. Spectrochim. Acta, Part A 2018, 202, 207-213.

(28) Lemon, C. M.; Powers, D. C.; Brothers, P. J.; Nocera, D. G. Gold Corroles as Near-IR Phosphors for Oxygen Sensing. Inorg. Chem. 2017, 56, 10991-10997.

(29) Jaworska, E.; Naitana, M. L.; Stelmach, E.; Pomarico, G.; Wojciechowski, M.; Bulska, E.; Maksymiuk, K.; Paolesse, R.; Michalska, A. Introducing Cobalt(II) Porphyrin/Cobalt(III) Corrole Containing Transducers for Improved Potential Reproducibility and Performance of All-Solid-State Ion-Selective Electrodes. Anal. Chem. 2017, 89, 7107-7114.

(30) Barbe, J.-M.; Canard, G.; Brandès, S.; Guilard, R. Selective Chemisorption of Carbon Monoxide by Organic-Inorganic Hybrid Materials Incorporating Cobalt(III) Corroles as Sensing Components. Chem. - Eur. J. 2007, 13, 2118-2129.

(31) Paolesse, R.; Nardis, S.; Monti, D.; Stefanelli, M.; Di Natale, C. Porphyrinoids for Chemical Sensor Applications. Chem. Rev. 2017, 117, 2517-2583.

(32) Vanotti, M.; Blondeau-Patissier, V.; Rabus, D.; Rauch, J.-Y.; Barbe, J.-M.; Ballandras, S. Development of Acoustic Devices Functionalized with Cobalt Corroles or Metalloporphyrines for the Detection of Carbon Monoxide at Low Concentration. Sens. Transducers 2012, 14, 197-211.

(33) Brandès, S.; Quesneau, V.; Fonquernie, O.; Desbois, N.; Blondeau-Patissier, V.; Gros, C. P. Porous Organic Polymers Based on Cobalt Corroles for Carbon Monoxide Binding. Dalton Trans. 2019, 48, 11651-11662.

(34) Blondeau-Patissier, V.; Vanotti, M.; Prêtre, T.; Rabus, D.; Tortora, L.; Barbe, J. M.; Ballandras, S. Detection and Monitoring of Carbon Monoxide Using Cobalt Corroles Film on Love Wave Devices with Delay Line Configuration. Procedia Eng. 2011, 25, 1085-1088.

(35) Barbe, J.-M.; Canard, G.; Brandès, S.; Guilard, R. OrganicInorganic Hybrid Sol-Gel Materials Incorporating Functionalized Cobalt(III) Corroles for the Selective Detection of CO. Angew. Chem., Int. Ed. 2005, 44, 3103-3106.

(36) Barbe, J.-M.; Canard, G.; Brandès, S.; Jérôme, F.; Dubois, G.; Guilard, R. Metallocorroles as Aensing Components for Gas Sensors:
Remarkable Affinity and Selectivity of Cobalt(III) Corroles for CO vs. $\mathrm{O}_{2}$ and $\mathrm{N}_{2}$. Dalton Trans. 2004, 1208-1214.

(37) Ganguly, S.; Renz, D.; Giles, L. J.; Gagnon, K. J.; McCormick, L. J.; Conradie, J.; Sarangi, R.; Ghosh, A. Cobalt- and RhodiumCorrole-Triphenylphosphine Complexes Revisited: The Question of a Noninnocent Corrole. Inorg. Chem. 2017, 56, 14788-14800.

(38) Ganguly, S.; Conradie, J.; Bendix, J.; Gagnon, K. J.; McCormick, L. J.; Ghosh, A. Electronic Structure of CobaltCorrole-Pyridine Complexes: Noninnocent Five-Coordinate Co(II) Corrole-Radical States. J. Phys. Chem. A 2017, 121, 9589-9598.

(39) Zakharieva, O.; Schünemann, V.; Gerdan, M.; Licoccia, S.; Cai, S.; Walker, F. A.; Trautwein, A. X. Is the Corrolate Macrocycle Innocent or Noninnocent? Magnetic Susceptibility, Mössbauer, ${ }^{1} \mathrm{H}$ NMR, and DFT Investigations of Chloro- and Phenyliron Corrolates. J. Am. Chem. Soc. 2002, 124, 6636-6648.

(40) Rovira, C.; Kunc, K.; Hutter, J.; Parrinello, M. Structural and Electronic Properties of Co-corrole, Co-corrin, and Co-porphyrin. Inorg. Chem. 2001, 40, 11-17.

(41) Lyaskovskyy, V.; de Bruin, B. Redox Non-Innocent Ligands: Versatile New Tools to Control Catalytic Reactions. ACS Catal. 2012, 2, 270-279.

(42) Pomarico, G.; Galloni, P.; Mandoj, F.; Nardis, S.; Stefanelli, M.; Vecchi, A.; Lentini, S.; Cicero, D. O.; Cui, Y.; Zeng, L.; Kadish, K. M.; Paolesse, R. 5,10,15-Triferrocenylcorrole Complexes. Inorg. Chem. 2015, 54, 10256-10268.

(43) Yadav, P.; Sankar, M.; Ke, X.; Cong, L.; Kadish, K. M. Highly Reducible $\pi$-Extended Copper Corroles. Dalton Trans. 2017, 46, 10014-10022.

(44) Thomas, K. E.; Vazquez-Lima, H.; Fang, Y.; Song, Y.; Gagnon, K. J.; Beavers, C. M.; Kadish, K. M.; Ghosh, A. Ligand Noninnocence in Coinage Metal Corroles: A Silver Knife-Edge. Chem. - Eur. J. 2015, 21, 16839-16847.

(45) Jiang, X.; Shan, W.; Desbois, N.; Quesneau, V.; Brandès, S.; Caemelbecke, E. V.; Osterloh, W. R.; Blondeau-Patissier, V.; Gros, C. P.; Kadish, K. M. Mono-DMSO Ligated Cobalt Nitrophenylcorroles: Electrochemical and Spectral Characterization. New J. Chem. 2018, 42, 8220-8229.

(46) Jiang, X.; Naitana, M. L.; Desbois, N.; Quesneau, V.; Brandès, S.; Rousselin, Y.; Shan, W.; Osterloh, W. R.; Blondeau-Patissier, V.; Gros, C. P.; Kadish, K. M. Electrochemistry of Bis(pyridine)cobalt (Nitrophenyl)corroles in Nonaqueous Media. Inorg. Chem. 2018, 57, 1226-1241.

(47) Osterloh, W. R.; Quesneau, V.; Desbois, N.; Brandès, S.; Shan, W.; Blondeau-Patissier, V.; Paolesse, R.; Gros, C. P.; Kadish, K. M. Synthesis and the Effect of Anions on the Spectroscopy and Electrochemistry of Mono(dimethyl sulfoxide)-Ligated Cobalt Corroles. Inorg. Chem. 2020, 59, 595-611.

(48) Van Caemelbecke, E.; Will, S.; Autret, M.; Adamian, V. A.; Lex, J.; Gisselbrecht, J.-P.; Gross, M.; Vogel, E.; Kadish, K. M. Electrochemical and Spectral Characterization of Iron Corroles in High and Low Oxidation States: First Structural Characterization of an Iron(IV) Tetrapyrrole $\pi$ Cation Radical. Inorg. Chem. 1996, 35, 184-192.

(49) Kadish, K. M.; Adamian, V. A.; Van Caemelbecke, E.; Gueletii, E.; Will, S.; Erben, C.; Vogel, E. Electrogeneration of Oxidized Corrole Dimers. Electrochemistry of (OEC)M Where $\mathrm{M}=\mathrm{Mn}, \mathrm{Co}$, $\mathrm{Ni}$, or $\mathrm{Cu}$ and OEC Is the Trianion of $2,3,7,8,12,13,17,18$ Octaethylcorrole. J. Am. Chem. Soc. 1998, 120, 11986-11993.

(50) Autret, M.; Will, S.; Caemelbecke, E. V.; Lex, J.; Gisselbrecht, J.-P.; Gross, M.; Vogel, E.; Kadish, K. M. Synthesis and Electrochemistry of Iron(III) Corroles Containing a Nitrosyl Axial Ligand. Spectral Characterization of $\left[(\mathrm{OEC}) \mathrm{Fe}^{\mathrm{III}}(\mathrm{NO})\right]^{\mathrm{n}}$ where $\mathrm{n}=0,1,2$, or -1 and OEC is the Trianion of 2,3,7,8,12,13,17,18-Octaethylcorrole. J. Am. Chem. Soc. 1994, 116, 9141-9149.

(51) Mahammed, A.; Botoshansky, M.; Gross, Z. Chlorinated Corroles. Dalton Trans. 2012, 41, 10938-10940.

(52) Norheim, H.-K.; Capar, J.; Einrem, R. F.; Gagnon, K. J.; Beavers, C. M.; Vazquez-Lima, H.; Ghosh, A. Ligand Noninnocence 
in FeNO Corroles: Insights from $\beta$-octabromocorrole Complexes. Dalton Trans. 2016, 45, 681-689.

(53) Ganguly, S.; Giles, L. J.; Thomas, K. E.; Sarangi, R.; Ghosh, A. Ligand Noninnocence in Iron Corroles: Insights from Optical and Xray Absorption Spectroscopies and Electrochemical Redox Potentials. Chem. - Eur. J. 2017, 23, 15098-15106.

(54) Solis, B. H.; Maher, A. G.; Honda, T.; Powers, D. C.; Nocera, D. G.; Hammes-Schiffer, S. Theoretical Analysis of Cobalt Hangman Porphyrins: Ligand Dearomatization and Mechanistic Implications for Hydrogen Evolution. ACS Catal. 2014, 4, 4516-4526.

(55) Sudhakar, K.; Mahammed, A.; Fridman, N.; Gross, Z. Trifluoromethylation for Affecting the Structural, Electronic and Redox Properties of Cobalt Corroles. Dalton Trans. 2019, 48, 47984810.

(56) Huang, S.; Fang, Y.; Lü, A.; Lu, G.; Ou, Z.; Kadish, K. M. Synthesis, Characterization and Solvent/Structural Effects on Spectral and Redox Properties of Cobalt Triphenylcorroles in Nonaqueous Media. J. Porphyrins Phthalocyanines 2012, 16, 958-967.

(57) Ganguly, S.; Ghosh, A. Seven Clues to Ligand Noninnocence: The Metallocorrole Paradigm. Acc. Chem. Res. 2019, 52, 2003-2014.

(58) Quesneau, V.; Shan, W.; Desbois, N.; Brandès, S.; Rousselin, Y.; Vanotti, M.; Blondeau-Patissier, V.; Naitana, M.; Fleurat-Lessard, P.; Van Caemelbecke, E.; Kadish, K. M.; Gros, C. P. Cobalt Corroles with Bis-Ammonia or Mono-DMSO Axial Ligands. Electrochemical, Spectroscopic Characterizations and Ligand Binding Properties. Eur. J. Inorg. Chem. 2018, 2018, 4265-4277.

(59) Ellis, P. E.; Linard, J. E.; Szymanski, T.; Jones, R. D.; Budge, J. R.; Basolo, F. Axial Ligation Constants of Iron(II) and Cobalt(II) "Capped" Porphyrins. J. Am. Chem. Soc. 1980, 102, 1889-1896.

(60) Frisch, M. J.; Trucks, G. W.; Schlegel, H. B.; Scuseria, G. E.; Robb, M. A.; Cheeseman, J. R.; Scalmani, G.; Barone, V.; Petersson, G. A.; Nakatsuji, H.; Li, X.; Caricato, M.; Marenich, A. V.; Bloino, J.; Janesko, B. G.; Gomperts, R.; Mennucci, B.; Hratchian, H. P.; Ortiz, J. V.; Izmaylov, A. F.; Sonnenberg, J. L.; Williams; Ding, F.; Lipparini, F.; Egidi, F.; Goings, J.; Peng, B.; Petrone, A.; Henderson, T.; Ranasinghe, D.; Zakrzewski, V. G.; Gao, J.; Rega, N.; Zheng, G.; Liang, W.; Hada, M.; Ehara, M.; Toyota, K.; Fukuda, R.; Hasegawa, J.; Ishida, M.; Nakajima, T.; Honda, Y.; Kitao, O.; Nakai, H.; Vreven, T.; Throssell, K.; Montgomery, J. A., Jr.; Peralta, J. E.; Ogliaro, F.; Bearpark, M. J.; Heyd, J. J.; Brothers, E. N.; Kudin, K. N.; Staroverov, V. N.; Keith, T. A.; Kobayashi, R.; Normand, J.; Raghavachari, K.; Rendell, A. P.; Burant, J. C.; Iyengar, S. S.; Tomasi, J.; Cossi, M.; Millam, J. M.; Klene, M.; Adamo, C.; Cammi, R.; Ochterski, J. W.; Martin, R. L.; Morokuma, K.; Farkas, O.; Foresman, J. B.; Fox, D. J. Gaussian 16, Rev. B.01; Guassian, Inc: Wallingford, CT, 2016.

(61) Zhao, Y.; Truhlar, D. G. The M06 Suite of Density Functionals for Main Group Thermochemistry, Thermochemical Kinetics, Noncovalent Interactions, Excited States, and Transition Elements: Two New Functionals and Systematic Testing of Four M06-Class Functionals and 12 Other Functionals. Theor. Chem. Acc. 2008, 120, 215-241.

(62) Cossi, M.; Barone, V.; Cammi, R.; Tomasi, J. Ab Initio Study of Solvated Molecules: A New Implementation of the Polarizable Continuum Model. Chem. Phys. Lett. 1996, 255, 327-335.

(63) Lipparini, F.; Scalmani, G.; Mennucci, B.; Cancès, E.; Caricato, M.; Frisch, M. J. A Variational Formulation of the Polarizable Continuum Model. J. Chem. Phys. 2010, 133, 014106.

(64) Dunning, T. H. Gaussian Basis Sets for Use in Correlated Molecular Calculations. I. The Atoms Boron Through Neon and Hydrogen. J. Chem. Phys. 1989, 90, 1007-1023.

(65) Balabanov, N. B.; Peterson, K. A. Systematically Convergent Basis Sets for Transition Metals. I. All-Electron Correlation Consistent Basis Sets for the $3 d$ Elements $\mathrm{Sc}-\mathrm{Zn}$. J. Chem. Phys. 2005, 123, 064107.

(66) Papajak, E.; Zheng, J.; Xu, X.; Leverentz, H. R.; Truhlar, D. G. Perspectives on Basis Sets Beautiful: Seasonal Plantings of Diffuse Basis Functions. J. Chem. Theory Comput. 2011, 7, 3027-3034.

(67) Grimme, S.; Antony, J.; Ehrlich, S.; Krieg, H. A Consistent and Accurate $A b$ Initio Parametrization of Density Functional Dispersion
Correction (DFT-D) for the 94 Elements H-Pu. J. Chem. Phys. 2010, 132, 154104.

(68) Weigend, F.; Ahlrichs, R. Balanced Basis Sets of Split Valence, Triple Zeta Valence and Quadruple Zeta Valence Quality for H to Rn: Design and Assessment of Accuracy. Phys. Chem. Chem. Phys. 2005, 7, 3297-3305.

(69) Zhurko, G. A., Zhurko, D. A. ChemCraft, Ver. 1.8; 2017; http://www.chemcraftprog.com.

(70) Murakami, Y.; Matsuda, Y.; Sakata, K.; Yamada, S.; Tanaka, Y.; Aoyama, Y. Transition-metal Complexes of Pyrrole Pigments. XVII. Preparation and Spectroscopic Properties of Corrole Complexes. Bull. Chem. Soc. Jpn. 1981, 54, 163-169.

(71) Nakamoto, K. Infrared and Raman Spectra of Inorganic Coordination Compounds, 3rd ed.; John Wiley \& Sons, Inc.: New York, 1977; pp 259-269.

(72) Ramdhanie, B.; Telser, J.; Caneschi, A.; Zakharov, L. N.; Rheingold, A. L.; Goldberg, D. P. An Example of $\mathrm{O}_{2}$ Binding in a Cobalt(II) Corrole System and High-Valent Cobalt-Cyano and Cobalt-Alkynyl Complexes. J. Am. Chem. Soc. 2004, 126, 25152525.

(73) Ooi, S.; Adinarayana, B.; Shimizu, D.; Tanaka, T.; Osuka, A. Stable meso-meso Linked $2 \mathrm{NH}$-Corrole Radical Dimers as a Key Intermediate to Corrole Tape. Angew. Chem. Int. Ed. 2020. DOI: 10.1002/anie.202002976

(74) Kadish, K. M.; Shao, J.; Ou, Z.; Gros, C. P.; Bolze, F.; Barbe, J.M.; Guilard, R. Alkyl- and Aryl-Substituted Corroles. 4. Solvent Effects on the Electrochemical and Spectral Properties of Cobalt Corroles. Inorg. Chem. 2003, 42, 4062-4070.

(75) Adamian, V. A.; D’Souza, F.; Licoccia, S.; Di Vona, M. L.; Tassoni, E.; Paolesse, R.; Boschi, T.; Kadish, K. M. Synthesis, Characterization, and Electrochemical Behavior of (5,10,15-Tri-Xphenyl-2,3,7,8,12,13,17,18-octamethylcorrolato)cobalt(III) Triphenylphosphine Complexes, Where $\mathrm{X}=p-\mathrm{OCH}_{3}, p-\mathrm{CH}_{3}, p-\mathrm{Cl}, m-\mathrm{Cl}$, $o$-Cl, $m$-F, or o-F. Inorg. Chem. 1995, 34, 532-540.

(76) Zuman, P. Substituent Effects in Organic Polarography; Plenum Press: New York, 1967.

(77) Kadish, K. M.; Lin, X. Q.; Han, B. C. Chloride-Binding Reactions and Electrochemistry of (Tetraphenylporphyrinato)cobalt and Chloro(tetraphenylporphyrinato)Cobalt in Dichloromethane. Inorg. Chem. 1987, 26, 4161-4167.

(78) Maiya, G. B.; Han, B. C.; Kadish, K. M. Electrochemical Studies of Cobalt-Carbon Bond Formation. A Kinetic Investigation of the Reaction between (Tetraphenylporphinato)cobalt(I) and Alkyl Halides. Langmuir 1989, 5, 645-650.

(79) Kadish, K. M.; Han, B. C.; Endo, A. Electrochemistry of Fiveand Six-coordinate $\sigma$-bonded Cobalt Porphyrins. Reactions of (TPP) $\mathrm{Co}\left(\mathrm{C}_{2} \mathrm{H}_{5}\right)(\mathrm{py})$ and (TPP) $\mathrm{Co}(\mathrm{R})$ where TPP is the Dianion of Tetraphenylporphyrin and $\mathrm{R}=\mathrm{CH}_{3}, \mathrm{C}_{2} \mathrm{H}_{5}$, or $\mathrm{CH}_{2} \mathrm{Cl}$. Inorg. Chem. 1991, 30, 4502-4506.

(80) Ke, X.; Kumar, R.; Sankar, M.; Kadish, K. M. Electrochemistry and Spectroelectrochemistry of Cobalt Porphyrins with $\pi$-Extending and/or Highly Electron-Withdrawing Pyrrole Substituents. In Situ Electrogeneration of $\sigma$-Bonded Complexes. Inorg. Chem. 2018, 57, $1490-1503$.

(81) Ghosh, A.; Wondimagegn, T.; Parusel, A. B. J. Electronic Structure of Gallium, Copper, and Nickel Complexes of Corrole. High-Valent Transition Metal Centers versus Noninnocent Ligands. J. Am. Chem. Soc. 2000, 122, 5100-5104.

(82) Mondal, B.; Ye, S. Hidden Ligand Noninnocence: A Combined Spectroscopic and Computational Perspective. Coord. Chem. Rev. 2020, 405, 213115.

(83) Kadish, K. M.; Bottomley, L. A.; Beroiz, D. Reactions of Pyridine with a Series of para-Substituted Tetraphenylporphyrincobalt and -Iron Complexes. Inorg. Chem. 1978, 17, 1124-1129.

(84) Kadish, K. M.; Morrison, M. M. Solvent and Substituent Effects on the Redox Reactions of para-Substituted Tetraphenylporphyrin. J. Am. Chem. Soc. 1976, 98, 3326-3328. 
(85) Kadish, K. M.; Morrison, M. M. Substituent Effects on the Oxidation-Reduction Reactions of Nickel para-Substituted Tetraphenylporphyrin in Nonaqueous Media. Inorg. Chem. 1976, 15, 980-982.

(86) Kadish, K. M.; Morrison, M. M. Substituent Effects on the Redox Reactions of Tetraphenylporphyrins. Bioinorg. Chem. 1977, 7, $107-115$.

(87) Vazquez-Lima, H.; Norheim, H.-K.; Einrem, R. F.; Ghosh, A. Cryptic Noninnocence: FeNO Corroles in a New Light. Dalton Trans. 2015, 44, 10146-10151.

(88) Ganguly, S.; MCormick, L. J.; Conradie, J.; Gagnon, K. J.; Sarangi, R.; Ghosh, A. Electronic Structure of Manganese Corroles Revisited: X-ray Structures, Optical and X-ray Absorption Spectroscopies, and Electrochemistry as Probes of Ligand Noninnocence. Inorg. Chem. 2018, 57, 9656-9669.

(89) Hammett, L. P. Physical Organic Chemistry; Wiley: New York, 1970.

(90) Senge, M. O. Highly Substituted Porphyrins. In The Porphyrin Handbook, Vol. 1; Kadish, K. M., Smith, K. M., Guilard, R., Eds.; Academic Press: Burlington, MA, 2000; Vol. 1, pp 239-335.

(91) Kadish, K. M.; Franzen, M. M.; Han, B. C.; Araullo-McAdams, C.; Sazou, D. Effect of the Porphyrin Macrocycle on the Spectroscopic Properties and Catalytic Activity of Electroreduced Nickel(II) Porphyrins. Inorg. Chem. 1992, 31, 4399-4403.

(92) Ghosh, A.; Halvorsen, I.; Nilsen, H. J.; Steene, E.; Wondimagegn, T.; Lie, R.; van Caemelbecke, E.; Guo, N.; Ou, Z.; Kadish, K. M. Electrochemistry of Nickel and Copper $\beta$ Octahalogeno-meso-tetraarylporphyrins. Evidence for Important Role Played by Saddling-Induced Metal $\left(\mathrm{d}_{\mathrm{x} 2-\mathrm{y} 2}\right)$-Porphyrin(" $\mathrm{a}_{2 \mathrm{u}}$ ") Orbital Interactions. J. Phys. Chem. B 2001, 105, 8120-8124.

(93) Kadish, K. M.; Lin, M.; Caemelbecke, E. V.; De Stefano, G.; Medforth, C. J.; Nurco, D. J.; Nelson, N. Y.; Krattinger, B.; Muzzi, C. M.; Jaquinod, L.; Xu, Y.; Shyr, D. C.; Smith, K. M.; Shelnutt, J. A. Influence of Electronic and Structural Effects on the Oxidative Behavior of Nickel Porphyrins. Inorg. Chem. 2002, 41, 6673-6687.

(94) Shelnutt, J. A.; Song, X.-Z.; Ma, J.-G.; Jia, S.-L.; Jentzen, W.; Medforth, C. J. Nonplanar Porphyrins and their Significance in Proteins. Chem. Soc. Rev. 1998, 27, 31-42.

(95) Walker, F. A.; Beroiz, D.; Kadish, K. M. Electronic Effects in Transition Metal Porphyrins. 2. The Sensitivity of Redox and Ligand Addition Reactions in para-Substituted Tetraphenylporphyrin Complexes of Cobalt(II). J. Am. Chem. Soc. 1976, 98, 3484-3489. 